\title{
Traveler delay costs and value of time with trip chains, flexible activity scheduling and information
}

\author{
Erik Jenelius $^{\mathrm{a}, *}$, Lars-Göran Mattsson ${ }^{\mathrm{a}}$, David Levinson ${ }^{\mathrm{b}}$ \\ ${ }^{a}$ Dept. of Transport Science, KTH Royal Institute of Technology, Teknikringen 72, SE-100 44 Stockholm, Sweden \\ ${ }^{\mathrm{b}}$ Dept. of Civil Engineering, University of Minnesota, USA
}

\section{A R T I C L E I N F O}

\section{Article history:}

Received 15 March 2010

Received in revised form 9 February 2011

Accepted 9 February 2011

\section{Keywords:}

Congestion

Disruption

Delay cost

Reliability

Schedule

Value of time

\begin{abstract}
A B S T R A C T
The delay costs of traffic disruptions and congestion and the value of travel time reliability are typically evaluated using single trip scheduling models, which treat the trip in isolation of previous and subsequent trips and activities. In practice, however, when activity scheduling to some extent is flexible, the impact of delay on one trip will depend on the actual and predicted travel time on itself as well as other trips, which is important to consider for long-lasting disturbances and when assessing the value of travel information. In this paper we extend the single trip approach into a two trips chain and activity scheduling model. Preferences are represented as marginal activity utility functions that take scheduling flexibility into account. We analytically derive trip timing optimality conditions, the value of travel time and schedule adjustments in response to travel time increases. We show how the single trip models are special cases of the present model and can be generalized to a setting with trip chains and flexible scheduling. We investigate numerically how the delay cost depends on the delay duration and its distribution on different trips during the day, the accuracy of delay prediction and travel information, and the scheduling flexibility of work hours. The extension of the model framework to more complex schedules is discussed.
\end{abstract}

(c) 2011 Elsevier Ltd. All rights reserved.

\section{Introduction}

Recurrent and non-recurrent congestion and disruptions in the transportation system, caused by for example adverse weather conditions, vehicle crashes, public events or technical failures, can have significant societal impacts. Losses of capacity or peaks in travel demand may lead to travel time increases that spread to the surrounding transportation network through congestion and queues. For individuals, delays can impair the ability to commute to work and take part in other daily activities such as dropping off and picking up children from daycare, shopping, or meeting friends. For businesses, negative impacts arise from delayed deliveries and supplies, loss of manpower and customers, increased freight costs, etc. (FWHA, 2008).

Thus, there are costs associated with the journey delays on a given day, as well as with the day-to-day uncertainty and variability of travel times, which causes users to depart earlier than preferred or take other precautions to reduce the risk of arriving late at their destinations. ${ }^{1}$ It follows that policies and investments that reduce the frequency, magnitude and impacts

\footnotetext{
* Corresponding author. Tel.: +46 8790 9635; fax: +46 87907002.

E-mail address: erik.jenelius@abe.kth.se (E. Jenelius).

1 Unless otherwise stated, the term delay refers throughout the paper to journey delay, i.e., travel time in excess of the normal travel time. Depending on how the traveler adjusts her schedule, journey delay may result in schedule delay, i.e., late or early arrival.
} 
of delays, such as congestion charges, ITS services and infrastructure reinforcements, can have significant economic benefits; however, these benefits need to be assessed.

The value of travel time variability (or conversely, reliability) has been studied extensively in recent years. A common approach is based on the single trip scheduling model proposed by Vickrey (1969) and Small (1982). In this model, in addition to a normal value of time, lateness or earliness costs arise proportionally to the difference between the actual arrival time and a preferred arrival time (PAT), sometimes with an additional discrete lateness penalty. The travel time is treated as stochastic, and the traveler is assumed to schedule her trip in order to minimize her expected cost. From this model, the value of travel time variability can be found theoretically (e.g., Noland and Small, 1995; Bates et al., 2001; Fosgerau and Karlström, 2010) and empirically (e.g., Bates et al., 2001; Asensio and Matas, 2008; Börjesson and Eliasson, 2011). ${ }^{2}$

Recently, Fosgerau and Engelson (2011) proposed the single trip scheduling model originally formulated by Vickrey (1973), in which the marginal costs of departing earlier from the origin or arriving later at the destination are linear functions of time, as an alternative to the Vickrey (1969) model for the valuation of travel time variability. Tseng and Verhoef (2008) estimate a more general model, in which marginal costs are allowed to vary non-linearly, for the morning commute using non-parametric methods. These models more clearly capture the fact that a trip is made between activities at both the origin and the destination. However, the models still only consider a single trip in isolation, assuming that marginal lateness and earliness costs are independent of previous and subsequent trips and activities.

Single trip scheduling models do not capture the fact that, in practice, the scheduling of many activities is at least partially flexible, so that the utility derived from them is not completely determined by the time of day they are undertaken. Flexible scheduling means that there are interactions between the travel conditions and timing of different parts of the daily trip chain which need to be considered. In particular, time lost on one trip need not be taken from the immediately following activity but can be distributed over several subsequent activities, or even, with advance information about the travel conditions, over previous activities. This is important for example in cases of significant disruptions which impose travel time increases on more than one trip during the day, such as both the morning and the evening commute. If delay occurs only on the morning trip, a flexible work schedule makes it possible to compensate for late arrival to work by working longer in the evening. If delay affects both commute trips, however, this restricts the possibility to make up for late arrival by working later, which should amount to higher costs per minute delay.

Scheduling flexibility is also important to consider when assessing the value of travel information provision as an instrument to alleviate the impacts of traffic disturbances. With flexible activity scheduling, the ideal timing of one trip may depend on the travel times of several subsequent trips during the day, which increases the influence of accurate predictions, and hence of information provision, about future travel conditions.

The aim of this paper is to generalize the single-trip modeling framework for the analysis of traveler delay costs and the value of travel time variability into a multiple trip model, taking the possibility of flexible activity scheduling into account. This represents an extension of the simple but analytically tractable single trip models into the field of activity-based travel demand modeling (Axhausen and Gärling, 1992; Bowman and Ben-Akiva, 2001; Ashiru et al., 2004; Ettema et al., 2007). We consider a daily schedule consisting of three activities, one of which may be flexible, and a chain of two intermediate trips. We use the model to analyse the case where travel times are deterministic and may depend on the departure times. We derive the optimality conditions for the timing of the trips and obtain analytical expressions for the value of travel time savings on each trip and optimal schedule adjustments in response to travel time increases.

Further, this paper shows how the single trip scheduling models above are special cases of the present model and can be generalized to a setting with trip chains and flexible scheduling. With model parameters calibrated against the empirical results of Tseng and Verhoef (2008), we investigate numerically how journey delay costs vary with delay duration depending on travelers' predictions about travel conditions. We also compare the impacts of a disruption affecting the morning and the evening commute symmetrically with disruptions affecting only one of the trips, to determine the value of being able to reschedule the remaining day following a delay.

The present model formulation is essentially equivalent to one of Ettema and Timmermans (2003). In their paper, however, the model was mainly used for numerical estimation of trip timing choices, and the authors did not fully work out its analytical properties. Specifically, the scheduling flexibility of work hours was introduced as a parameter in the model estimation once functional forms for the marginal utilities of activities had been specified, and they did not theoretically consider the effect of scheduling flexibility on the trip timing optimality conditions, the value of travel time and schedule adjustments in response to travel time changes.

It should be noted that the activity-based model of Ettema and Timmermans (2003) has been subsequently employed and further developed by others. Ashiru et al. (2004) present an extended theoretical framework also incorporating activity intensity and outline an algorithm for the activity scheduling problem. As in Ettema and Timmermans (2003), the scheduling flexibility only enters the analysis in a numerical illustration with the same assumed shape of the marginal activity utilities as in the former paper. Zhang et al. (2005) use the model to simulate travelers' choices of departure times on both the

\footnotetext{
2 Another common approach is to include some measure of travel time variability, such as the standard deviation or the 80th to the 50th percentile range, directly in individuals' utility functions (e.g., Noland and Polak, 2002; Small et al., 2005; Carrion-Madera and Levinson, 2010). For a recent review of the literature on the value of reliability, see Carrion-Madera and Levinson (2011).
} 
morning and the evening commute when travel times depend endogenously on travelers' trip timing in the form of bottleneck congestion. In particular, the authors study the impact of flexibility in work hours on the total queueing time and delay. Ettema et al. (2007) combine the scheduling model of Small (1982), time-of-day dependent marginal utility functions similar to Ettema and Timmermans (2003) and activity durations into an error component discrete choice activity scheduling model, which is estimated on empirical data.

The paper is organized as follows. In Section 2 the model is formulated and optimality conditions for the daily schedule, as well as analytical expressions for the value of travel time and optimal schedule adjustments, are derived. In Section 3 we consider the utility losses due to journey delay under different assumptions about traveler predictions of the delay. Section 4 presents a numerical example of the delay costs under different delay scenarios and traveler prediction profiles. The modeling approach, results and possible extensions are discussed and conclusions are drawn in Section 5.

\section{Theoretical model}

The modeling framework postulates that individuals spend the day taking part in activities and traveling between activities. A daily schedule is a sequence of activities and trips with a specified start time and duration for each activity and trip. The individuals have preferences among feasible schedules which are expressed with a utility function $U$.

The utility derived from taking part in an activity is assumed to be independent of other activities but to depend in general on both the time of day and on the duration of the participation. The utility gained from spending another unit of time on activity $i$ at time $t$ is expressed in the form of a marginal utility function $u_{i}\left(t ; t_{s i}\right)$, where $t_{s i}$ is the start time of the activity. Specifically and in accordance with Ettema and Timmermans (2003), we assume that the marginal utility depends on a linear combination of the time of day $t$ and the duration $t-t_{s i}$, i.e., $u_{i}\left(t-\xi_{i} t_{s i}\right)$, where $\xi_{i} \in[0,1]$ is a parameter expressing the scheduling flexibility of the activity. Note that $\xi_{i}=0$ means that marginal utility depends only on time of day, while $\xi_{i}=1$ means that marginal utility depends only on time since arrival, i.e., activity duration. Flexibility here thus refers to the degree to which the utility of taking part in an activity is independent of the time of day and is not associated with any particular assumption about the shape of the marginal utility function. In general, time-of-day dependencies arise from, e.g., benefits of coordination with others and fixed activity start and end hours. Duration dependencies arise from, e.g., start-up and fatigue effects.

The marginal utility derived from traveling, denoted $v$, is assumed to be constant. ${ }^{3}$ The time required to travel from activity $i$ to $i+1$ is deterministic and depends in general on the departure time $t_{\mathrm{di}}, T_{i}\left(t_{\mathrm{di}}\right)$. Similar to Noland and Small (1995) we may without loss of generality write the travel time on trip $i$ as the sum of a positive component $T_{i}$ that is independent of departure time and a non-negative congestion profile $T_{\mathrm{xi}}\left(t_{\mathrm{di} i}\right)$, i.e., $T_{i}\left(t_{\mathrm{d} i}\right)=T_{i}+T_{\mathrm{xi}}\left(t_{\mathrm{d} i}\right)$. To ensure that departing later cannot make a traveler arrive earlier (i.e., the FIFO principle) we require that $T_{i}^{\prime}(t)=T_{\mathrm{xi}}^{\prime}(t)>-1$.

In this paper we consider a daily schedule that consists of three activities and a chain of two intermediate trips. Although the model is quite general, we may interpret activity 1 as being at home in the morning, activity 2 as being at work during the day and activity 3 as being at home in the evening. Correspondingly, trips 1 and 2 may represent the commute from home to work in the morning and back in the evening, respectively.

We assume that the schedule of a day is independent of preceding and subsequent days. This means that we can fix two times $t=0$ and $t=1$ that mark the start and end of the day, respectively. There is thus no need to distinguish between timeof-day and duration-dependent utility for activities 1 and 3. For activity 2 we assume that the marginal utility at time $t$ depends on the duration $t-t_{\mathrm{s} 2}$ as well as the time of day $t$, where a parameter $\xi$, introduced above, expresses the scheduling flexibility.

For work trips, late arrival or early departure can have both short-run (e.g., penalties) and long-run negative impacts on the wage, which in turn would affect the available budget for consumption. Thus, it is reasonable to interpret $U$ as a partially indirect utility function, implicitly incorporating the consumption of goods for any income. The marginal utility of the work activity $u_{2}\left(t-\xi t_{\mathrm{s} 2}\right)$ then arises both from the direct utility derived from working and the effect on the direct utility from goods consumption through the budget constraint (cf. Small, 1982, 2010; Arentze et al., 2010).

In summary, we have the following notation:

$t_{\mathrm{d} i}$ departure time of trip $i$ (end time of activity $i$ ), $i=1,2$.

$T_{i}\left(t_{\mathrm{di}}\right)=T_{i}+T_{\mathrm{xi}}\left(t_{\mathrm{di}}\right)$ duration of trip $i$ as a function of departure time, $i=1,2$.

$t_{\mathrm{s}, i+1}=t_{\mathrm{d} i}+T_{i}\left(t_{\mathrm{di}}\right)$ start time of activity $i+1$ (arrival time of trip $\left.i\right), i=1,2$.

$u_{i}(t)$ marginal utility of activity $i$ at time $t, i=1,3$.

$u_{2}\left(t-\xi t_{\mathrm{s} 2}\right)$ marginal utility of activity 2 at time $t$, given start time $t_{\mathrm{s} 2}$ and scheduling flexibility $\xi$.

$v$ marginal utility of travel.

Fig. 1 illustrates a set of generic marginal utility functions that satisfy our assumptions above. Given that the number and sequence of activities have been fixed, the remaining decision variables for the individual are the durations of the activities

\footnotetext{
${ }^{3}$ This assumption can be generalized so that utility depends non-linearly on travel duration, as some empirical evidence suggests (e.g., Redmond and Mokhtarian, 2001). For the present analysis we lack the necessary data to employ such functions.
} 


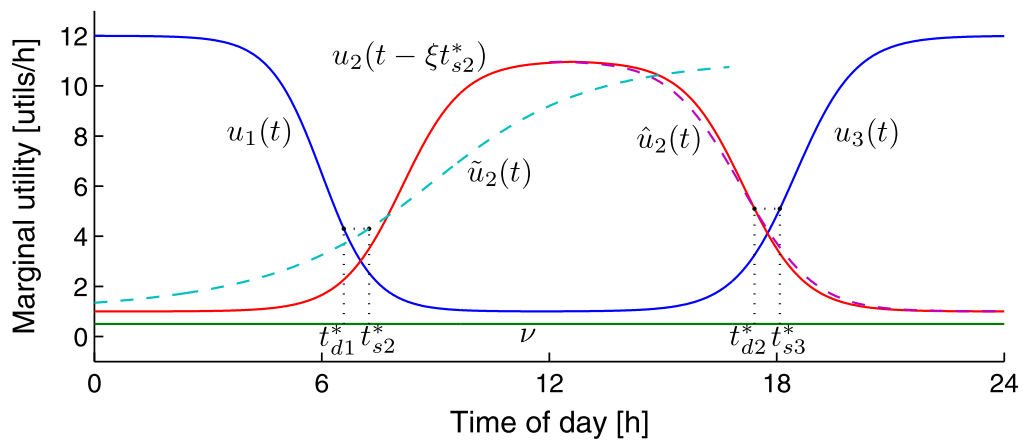

Fig. 1. A generic set of marginal utility functions with semi-flexible scheduling of activity $2(\xi=0.5)$. Dotted lines show the optimal timing of trips assuming $2 \times 40$ min travel times independent of departure times; dashed lines show the backward and forward optimal marginal utility functions (Section 2.1 ).

(where two durations determine the third) or, equivalently, the departure times of the two trips. The utility associated with the schedule $\left(t_{\mathrm{d} 1}, t_{\mathrm{d} 2}\right)$ is then

$$
U\left(t_{\mathrm{d} 1}, t_{\mathrm{d} 2} ; T_{1}, T_{2}\right) \equiv \int_{0}^{t_{\mathrm{d} 1}} u_{1}(t) d t+\int_{t_{\mathrm{d} 1}+T_{1}\left(t_{\mathrm{d} 1}\right)}^{t_{\mathrm{d} 2}} u_{2}\left(t-\xi\left[t_{\mathrm{d} 1}+T_{1}\left(t_{\mathrm{d} 1}\right)\right]\right) d t+\int_{t_{\mathrm{d} 2}+T_{2}\left(t_{\mathrm{d} 2}\right)}^{1} u_{3}(t) d t+v\left[T_{1}\left(t_{\mathrm{d} 1}\right)+T_{2}\left(t_{\mathrm{d} 2)]} .\right.\right.
$$

This model has, at least implicitly, been formulated previously by Ettema and Timmermans (2003) and Zhang et al. (2005). In the "operational model" of Ettema and Timmermans (2003), however, scheduling flexibility is not included, and its effects on trip timing, value of time, etc. are not considered. Zhang et al. (2005) perform no theoretical studies of the properties of the model but only use it for numerical simulation of departure time choices and endogenous congestion within a discrete choice framework.

\subsection{Optimal schedule}

Under normal, baseline travel conditions the individual chooses morning and evening departure times in order to maximize her utility. Thus, the individual solves

$$
\begin{array}{ll}
\max _{t_{\mathrm{d} 1}, t_{\mathrm{d} 2}} & U\left(t_{\mathrm{d} 1}, t_{\mathrm{d} 2} ; T_{1}, T_{2}\right) \\
\text { s.t. } & 0 \leqslant t_{\mathrm{d} 1} \leqslant 1, \\
& t_{\mathrm{d} 1}+T_{1}\left(t_{\mathrm{d} 1}\right) \leqslant t_{\mathrm{d} 2}, \\
& t_{\mathrm{d} 2}+T_{2}\left(t_{\mathrm{d} 2}\right) \leqslant 1 .
\end{array}
$$

Constraint (3) ensures that the traveler departs from activity 1 during the day, constraint (4) ensures that the traveler arrives at activity 2 before departing again, while constraint (5) ensures that the traveler arrives at activity 3 before the end of the day.

The marginal utility functions $u_{i}$ are assumed to be continuously differentiable, initially increasing for $i=2,3$ (representing a warm-up period) but ultimately decreasing for $i=1,2$ (representing a cool-down period), regardless of arrival time. With realistic utility functions and travel times the constraints will be non-binding (i.e., the individual will prefer to spend some time at home both in the morning and the evening, and some time at work), so that optimal departure times satisfy $\partial U / \partial t_{\mathrm{d} 1}=\partial U / \partial t_{\mathrm{d} 2}=0$.

To make the analysis more transparent, let us in the following consider the special case where travel time is independent of departure time, i.e, $T_{i}\left(t_{\mathrm{d} i}\right)=T_{i}$ for $i=1$, 2; we return to the general case in Section 2.4 and in Appendix A. If, in this special case, we assume that travel times are such that the individual can always depart during the cool-down period and arrive during the warm-up period of each activity, i.e., that $u_{1}^{\prime}\left(t_{\mathrm{d} 1}\right)<0, u_{2}^{\prime}\left([1-\xi] t_{\mathrm{s} 2}\right)>0, u_{2}^{\prime}\left(t_{\mathrm{d} 2}-\xi t_{\mathrm{s} 2}\right)<0$ and $u_{3}^{\prime}\left(t_{\mathrm{s} 3}\right)>0$, then the utility function is concave and there is a unique maximum.

For any scheduling flexibility $\xi$ the optimality conditions require that the departure times simultaneously satisfy

$$
\begin{aligned}
& u_{1}\left(t_{\mathrm{d} 1}^{*}\right)=[1-\xi] u_{2}\left([1-\xi] t_{\mathrm{s} 2}^{*}\right)+\xi u_{2}\left(t_{\mathrm{d} 2}^{*}-\xi t_{\mathrm{s} 2}^{*}\right), \\
& u_{2}\left(t_{\mathrm{d} 2}^{*}-\xi t_{\mathrm{s} 2}^{*}\right)=u_{3}\left(t_{\mathrm{s} 3}^{*}\right),
\end{aligned}
$$

where $t_{\mathrm{s} 2}^{*}=t_{\mathrm{d} 1}^{*}+T_{1}$ and $t_{\mathrm{s} 3}^{*}=t_{\mathrm{d} 2}^{*}+T_{2}$ are the arrival times associated with the optimal departure times $t_{\mathrm{d} 1}^{*}$ and $t_{\mathrm{d} 2}^{*}$. Note that in general the optimal timing of trip 1 depends on the departure time of trip 2, while the optimal timing of trip 2 depends on the arrival time of trip 1. Fig. 1 shows the optimal timing of both trips for a set of generic marginal utility functions with semi-flexible scheduling of activity 2, i.e., $\xi=0.5$. 
If activity 2 is completely fixed $(\xi=0)$ the optimality conditions give that $u_{1}\left(t_{\mathrm{d} 1}^{*}\right)=u_{2}\left(t_{\mathrm{s} 2}^{*}\right)$ and $u_{2}\left(t_{\mathrm{d} 2}^{*}\right)=u_{3}\left(t_{\mathrm{s} 3}^{*}\right)$, i.e., the marginal utilities at the origin and the destination activities must be equal for each trip (cf. Ettema and Timmermans, 2003; Tseng and Verhoef, 2008). In this special case the optimal timing of one trip is independent of the travel time and timing of the other trip.

In the other extreme, if the schedule is completely flexible $(\xi=1)$ optimal departure times will satisfy $u_{1}\left(t_{\mathrm{d} 1}^{*}\right)=$ $u_{2}\left(t_{\mathrm{d} 2}^{*}-t_{\mathrm{s} 2}^{*}\right)=u_{3}\left(t_{\mathrm{s} 3}^{*}\right)$. That is, since the departure time from activity 1 and the arrival time to activity 3 are in one-to-one correspondence with the duration of the respective activity, the marginal utility of the duration of each activity must be equal. This result is often obtained from pure time allocation models, e.g., Jara-Diaz et al. (2008).

Given that the traveler arrives to activity 2 at $t_{\mathrm{s} 2}$ (not necessarily the optimal arrival time $t_{\mathrm{s} 2}^{*}$ ), there is an optimal departure time from that activity, $t_{\mathrm{d} 2}^{*}\left(t_{\mathrm{s} 2}\right)$, and an associated arrival time to activity $3, t_{\mathrm{s} 3}^{*}\left(t_{\mathrm{s} 2}\right)$. It will be useful in the following to calculate the marginal effect on utility of a change in the arrival time $t_{\mathrm{s} 2}$, assuming that trip 2 is optimally timed in response to the change. Thus, let $\widetilde{U}_{2}\left(t_{\mathrm{s} 2}, t_{\mathrm{d} 2}\right)$ be the utility derived from time $t_{\mathrm{s} 2}$ to the end of the day. We then introduce the "backward optimal" marginal utility function $\tilde{u}_{2}\left(t_{\mathrm{s} 2}\right)=-d \widetilde{U}_{2}\left(t_{\mathrm{s} 2}, t_{\mathrm{d} 2}^{*}\left(t_{\mathrm{s} 2}\right)\right) / d t_{\mathrm{s} 2}$, which is the marginal change in subsequent utility due to an earlier arrival time. From the envelope theorem (e.g., Mas-Colell et al., 1995) it follows that $\tilde{u}_{2}\left(t_{\mathrm{s} 2}\right)$ is given by

$$
\tilde{u}_{2}\left(t_{\mathrm{s} 2}\right)=[1-\xi] u_{2}\left([1-\xi] t_{\mathrm{s} 2}\right)+\xi u_{2}\left(t_{\mathrm{d} 2}^{*}\left(t_{\mathrm{s} 2}\right)-\xi t_{\mathrm{s} 2}\right) .
$$

The optimality condition (6) can thus be summarized as $u_{1}\left(t_{\mathrm{d} 1}^{*}\right)=\tilde{u}_{2}\left(t_{\mathrm{s} 2}^{*}\right)$. This can be seen as a dynamic programming approach to optimizing the daily activity schedule, which is generalizable to more complex schedules (see, e.g., Karlström, $2005)$. Note that $\tilde{u}_{2}\left(t_{\mathrm{s} 2}\right)=u_{2}\left(t_{\mathrm{s} 2}\right)$ with $\xi=0$ and $\tilde{u}_{2}\left(t_{\mathrm{s} 2}\right)=u_{2}\left(t_{\mathrm{d} 2}^{*}\left(t_{\mathrm{s} 2}\right)-t_{\mathrm{s} 2}\right)$ with $\xi=1$.

For cases where the preceding day can be optimally scheduled in response to changes in the departure time on trip 2, a corresponding "forward optimal" marginal utility function $\hat{u}_{2}\left(t_{\mathrm{d} 2}\right)$ can be defined as shown in Appendix A. With this function the optimality condition (7) can be written as $\hat{u}_{2}\left(t_{\mathrm{d} 2}^{*}\right)=u_{3}\left(t_{\mathrm{s} 3}^{*}\right)$. Fig. 1 shows $\tilde{u}_{2}\left(t_{\mathrm{s} 2}\right)$ and $\hat{u}_{2}\left(t_{\mathrm{d} 2}\right)$ for an example set of utility functions.

\subsection{Value of travel time}

An increase in travel time affects utility not only through the marginal utility of travel but also through the reduction in activity participation that must occur due to the limited time available in a day (e.g., Jara-Diaz, 2000). By definition, the utility derived from a daily schedule depends not only on the amount of time spent traveling and in activities but also on the timing of the activities and trips. To capture the full, long-run impact of an exogenous change in travel time, it is reasonable to calculate its value given that individuals adjust their schedule optimally to the change. The full effect on utility of a change in travel time is then $d U^{*} / d T$, where $U^{*}=U\left(t_{\mathrm{d} 1}^{*}, t_{\mathrm{d} 2}^{*} ; T_{1}, T_{2}\right)$ is the utility under the optimal schedule and $T$ is a generic travel time.

When needed in the following we will assume that the arbitrary scale of utility has been chosen such that $U$ is a money metric utility function, for example the compensating variation relative to some baseline situation. This means that a money value of time is simply $-d U^{*} / d T$. At any time $t$, differences among marginal utilities $u_{i}\left(t ; t_{s i}\right)$ and $v$ represent marginal monetary losses or gains of spending an additional unit time in one activity rather than the other (Tseng and Verhoef, 2008).

In general, the impact on utility depends on which trip travel time is changed on, since this determines which activities are most affected. In other words, the value of travel time varies between trips. On the other hand, the value of time on one trip generally depends on the baseline travel times on both trips from which the change occurs. From the envelope theorem, the value of saving time on each trip is

$$
\begin{aligned}
& -\frac{d U^{*}}{d T_{1}}=\tilde{u}_{2}\left(t_{\mathrm{s} 2}^{*}\right)-v, \\
& -\frac{d U^{*}}{d T_{2}}=u_{3}\left(t_{\mathrm{s} 3}^{*}\right)-v .
\end{aligned}
$$

If activity 2 is fixed $(\xi=0)$ we have $\tilde{u}_{2}\left(t_{\mathrm{s} 2}^{*}\right)=u_{2}\left(t_{\mathrm{s} 2}^{*}\right)$, and from the optimality conditions it follows that the value of saving travel time on one trip is independent of the travel time and timing of the other trip. If activity 2 is completely flexible $(\xi=1)$ we have $\tilde{u}_{2}\left(t_{\mathrm{s} 2}^{*}\right)=u_{2}\left(t_{\mathrm{d} 2}^{*}-t_{\mathrm{s} 2}^{*}\right)$, and since the optimality conditions require that $u_{2}\left(t_{\mathrm{d} 2}^{*}-t_{\mathrm{s} 2}^{*}\right)=u_{3}\left(t_{\mathrm{s} 3}^{*}\right)$, the value of saving travel time will be the same regardless of which trip travel time is saved on. In this special case there is thus a single value of time for both trips.

\subsection{Optimal schedule adjustments}

It is also of interest to know the optimal schedule adjustments in response to a change in travel time, i.e., $d t_{\mathrm{di}}^{*} / d T_{j}$ and $d t_{s, i+1}^{*} / d T_{j}, i, j=1,2$. Expressions for these are derived in Appendix A for the general case with departure time-dependent travel times. With our assumptions about the shape of the marginal utility functions, purely exogenous travel times mean that an increase in travel time moves the optimal departure and arrival times of the trip earlier and later, respectively; that is, $d t_{\mathrm{di}}^{*} / d T_{i}<0$ and $d t_{\mathrm{s}, i+1}^{*} / d T_{i}>0$ for $i=1,2$. Since $\tilde{u}_{2}\left(t_{\mathrm{s} 2}\right)$ and $u_{3}\left(t_{\mathrm{s} 3}\right)$ are increasing functions (the fact that $\tilde{u}_{2}\left(t_{\mathrm{s} 2}\right)$ is increasing 
is shown in Appendix A), this means that the value of time on each trip is increasing with the travel time. Empirical findings supporting this result have been reported by Small et al. (2005).

With $\xi=0$ the optimal departure time adjustment for each trip depends on the relative steepness of the marginal utilities of the origin and destination activities. That is, if the marginal utility decreases more steeply at the origin than it increases at the destination, more time will be taken from the latter activity, and vice versa,

$$
\frac{d t_{\mathrm{d} i} *}{d T_{i}}=\frac{u_{i+1}^{\prime}\left(t_{\mathrm{s}, i+1}^{*}\right)}{u_{i}^{\prime}\left(t_{\mathrm{d} i}^{*}\right)-u_{i+1}^{\prime}\left(t_{\mathrm{s}, i+1}^{*}\right)}, \quad \frac{d t_{\mathrm{s}, i+1}^{*}}{d T_{i}}=\frac{u_{i}^{\prime}\left(t_{\mathrm{d} i}^{*}\right)}{u_{i}^{\prime}\left(t_{\mathrm{d} i}^{*}\right)-u_{i+1}^{\prime}\left(t_{\mathrm{s}, i+1}^{*}\right)}, \quad \xi=0, i=1,2 .
$$

With $\xi=1$ time is taken from all three activities in proportions that are independent of which trip travel time is changed on and, again, determined by the relative steepness of the marginal utility functions,

$$
\begin{aligned}
& \frac{d t_{\mathrm{d} 1}^{*}}{d T_{i}}=\frac{u_{2}^{\prime}\left(t_{\mathrm{d} 2}^{*}-t_{\mathrm{s} 2}^{*}\right) u_{3}^{\prime}\left(t_{\mathrm{s} 3}^{*}\right)}{u_{1}^{\prime}\left(t_{\mathrm{d} 1}^{*}\right) u_{2}^{\prime}\left(t_{\mathrm{d} 2}^{*}-t_{\mathrm{s} 2}^{*}\right)-u_{1}^{\prime}\left(t_{\mathrm{d} 1}^{*}\right) u_{3}^{\prime}\left(t_{\mathrm{s} 3}^{*}\right)-u_{2}^{\prime}\left(t_{\mathrm{d} 2}^{*}-t_{\mathrm{s} 2}^{*}\right) u_{3}^{\prime}\left(t_{\mathrm{s} 3}^{*}\right)}, \\
& \frac{d\left[t_{\mathrm{d} 2}^{*}-t_{\mathrm{s} 2}^{*}\right]}{d T_{i}}=\frac{u_{1}^{\prime}\left(t_{\mathrm{d} 1}^{*}\right) u_{3}^{\prime}\left(t_{\mathrm{s} 3}^{*}\right)}{u_{1}^{\prime}\left(t_{\mathrm{d} 1}^{*}\right) u_{2}^{\prime}\left(t_{\mathrm{d} 2}^{*}-t_{\mathrm{s} 2}^{*}\right)-u_{1}^{\prime}\left(t_{\mathrm{d} 1}^{*}\right) u_{3}^{\prime}\left(t_{\mathrm{s} 3}^{*}\right)-u_{2}^{\prime}\left(t_{\mathrm{d} 2}^{*}-t_{\mathrm{s} 2}^{*}\right) u_{3}^{\prime}\left(t_{\mathrm{s} 3}^{*}\right)}, \\
& \frac{d t_{\mathrm{s} 3}^{*}}{d T_{i}}=\frac{u_{1}^{\prime}\left(t_{\mathrm{d} 1}^{*}\right) u_{2}^{\prime}\left(t_{\mathrm{d} 2}^{*}-t_{\mathrm{s} 2}^{*}\right)}{u_{1}^{\prime}\left(t_{\mathrm{d} 1}^{*}\right) u_{2}^{\prime}\left(t_{\mathrm{d} 2}^{*}-t_{\mathrm{s} 2}^{*}\right)-u_{1}^{\prime}\left(t_{\mathrm{d} 1}^{*}\right) u_{3}^{\prime}\left(t_{\mathrm{s} 3}^{*}\right)-u_{2}^{\prime}\left(t_{\mathrm{d} 2}^{*}-t_{\mathrm{s} 2}^{*}\right) u_{3}^{\prime}\left(t_{\mathrm{s} 3}^{*}\right)}, \quad \xi=1, i=1,2 .
\end{aligned}
$$

\subsection{Departure time-dependent travel times}

Results are less clear-cut in the general case when travel times depend on departure times. For example, without any further specification of the congestion profiles $T_{\mathrm{xi}}\left(t_{\mathrm{d} i}\right)$, the utility maximization problem is in general not concave and optimal schedules need not be unique.

For the study of the value of travel time, it is necessary to distinguish between the effect of an exogenous change in travel time and the endogenous dependency of travel time on departure time. In our analysis we assume that the exogenous change in travel time on a trip is uniform and independent of departure time. The direct effect of an exogenous change in travel time $d T_{i}$ is an equal change in arrival time $d t_{\mathrm{s}, i+1}=d T_{i}$. Meanwhile, the direct effect of a change in departure time $d t_{\mathrm{d} i}$ is a change in travel time $T_{\mathrm{x} i}^{\prime}\left(t_{\mathrm{d} i}\right) d t_{\mathrm{d} i}$ and arrival time $d t_{\mathrm{s}, i+1}=\left[1+T_{\mathrm{x} i}^{\prime}\left(t_{\mathrm{d} i}\right)\right] d t_{\mathrm{d} i}$. At optimum, an exogenous change in travel time can affect the departure time and thus induce an endogenous change in travel time as well, so that $d t_{s, i+1}^{*} / d T_{i}=1+$ $\left[1+T_{\mathrm{xi}}^{\prime}\left(t_{\mathrm{d} i}^{*}\right)\right] d t_{\mathrm{d} i}^{*} / d T_{i}$.

In Appendix A we show that formulas (9) and (10) for the marginal value of time remain valid in the general case. However, it is no longer necessarily true that an increase in travel time moves the optimal departure and arrival times on the trip earlier and later, respectively, nor that a completely flexible schedule $(\xi=1)$ implies a single value of time for both trips.

\subsection{Relationship with single trip scheduling models}

Tseng and Verhoef (2008) define the cost associated with a trip of a certain travel time and timing as the willingness to accept the trip in relation to an optimally timed instantaneous transition from origin to destination. Within our two trip chain model, it is reasonable to calculate the travel cost of trip 1 under the condition that trip 2 is timed optimally given the arrival time of trip 1 . If travel were instantaneous, the optimal time to travel, denoted $t^{*}$, would be the solution to $u_{1}\left(t^{*}\right)=\tilde{u}_{2}\left(t^{*}\right)$, i.e., the point in time when the marginal utility at activity 1 equals the backward optimal marginal utility of activity 2.

With a positive travel time, the marginal cost of travel at any time $t$ arises from the difference in the marginal utility of travel $v$ and the largest of $u_{1}(t)$ and $\tilde{u}_{2}(t)$, where $u_{1}(t)>\tilde{u}_{2}(t)$ for $t<t^{*}$ and $u_{1}(t)<\tilde{u}_{2}(t)$ for $t>t^{*}$. Introducing the marginal cost functions $\alpha_{1}(t) \equiv u_{1}(t)-v$ and $\tilde{\alpha}_{2}(t) \equiv \tilde{u}_{2}(t)-v$, the total cost of a trip starting at $t_{\mathrm{d} 1}$ and ending at $t_{\mathrm{s} 2}$ is

$$
C_{1}\left(t_{\mathrm{d} 1}, t_{\mathrm{s} 2}\right)=\int_{t_{\mathrm{d} 1}}^{t^{*}} \alpha_{1}(t) d t+\int_{t^{*}}^{t_{\mathrm{s} 2}} \tilde{\alpha}_{2}(t) d t
$$

or equivalently, with the marginal cost functions $\beta_{1}(t) \equiv u_{1}(t)-\tilde{u}_{2}(t)$ and $\gamma_{1}(t) \equiv \tilde{u}_{2}(t)-u_{1}(t)$,

$$
C_{1}\left(t_{\mathrm{d} 1}, t_{\mathrm{s} 2}\right)=\int_{t_{\mathrm{d} 1}}^{t_{\mathrm{s} 2}} \alpha_{1}(t) d t+ \begin{cases}\int_{t_{\mathrm{s} 2}}^{t^{*}} \beta_{1}(t) d t & \text { if } t_{\mathrm{s} 2}<t^{*} \\ \int_{t^{*}}^{t_{\mathrm{s} 2}} \gamma_{1}(t) d t & \text { if } t_{\mathrm{s} 2} \geqslant t^{*}\end{cases}
$$

Tseng and Verhoef (2008) derived the corresponding formula within their model for the timing of the morning commute, which is equivalent to the special case $\xi=0$ of our model. They thus did not consider the influence of subsequent trips on the timing problem, which means that $\tilde{u}_{2}(t)$ simplifies to $u_{2}(t)$. In Section 4.1 we make use of the relationship with the model of Tseng and Verhoef (2008) to calibrate the travel costs of the morning commute.

Travel costs are also captured in the scheduling model of Vickrey (1969) and Small (1982), where costs arise if an individual arrives before or after a preferred arrival time $t^{*}$. This specification, sometimes with an additional discrete lateness 
penalty, has been frequently used to calculate the value of travel time reliability when travel time $T$ is stochastic (e.g., Noland and Small, 1995; Fosgerau and Karlström, 2010). Specifically, the cost of a trip starting at time $t_{\mathrm{d}}$ and ending at time $t_{\mathrm{s}}=t_{\mathrm{d}}+T$ in that model is, for some parameters $\alpha, \beta$ and $\gamma$,

$$
C_{1}\left(t_{\mathrm{d}}, t_{\mathrm{s}}\right)=\alpha T+ \begin{cases}\beta\left[t^{*}-t_{\mathrm{s}}\right] & \text { if } t_{\mathrm{s}}<t^{*}, \\ \gamma\left[t_{\mathrm{s}}-t^{*}\right] & \text { if } t_{\mathrm{s}} \geqslant t^{*}\end{cases}
$$

It can be seen that the linear model (17) is obtained as a special case of (16) when the three marginal cost functions $\alpha_{1}(t)$, $\beta_{1}(t)$ and $\gamma_{1}(t)$ are constant over time. It can also serve as an approximation of (16) when the deviations from the normal travel time and trip timing are small. In the context of severe traffic disruptions, however, deviations may be very large and approximation errors may be significant if $\alpha_{1}(t), \beta_{1}(t)$ and $\gamma_{1}(t)$ vary over time as empirical evidence suggests (Tseng and Verhoef, 2008).

\subsection{Special case: linear marginal utilities}

An important special case of the general model is when marginal activity utilities are linear functions of time. This specification has been used, for a single trip, by Vickrey (1973) and recently by Fosgerau and Engelson (2011) who propose it as an alternative to the constant marginal utility scheduling model of Vickrey (1969) and Small (1982) above in the context of valuing travel time variability.

This model is the linear special case of the model of Tseng and Verhoef (2008) above. An attractive feature of the linear single trip specification is that closed form expressions exist for the optimal departure time, the value of (mean) travel time, and, in the case of stochastic travel times, the value of travel time variance Fosgerau and Engelson, 2011.

Thus, in the single trip model marginal utilities are specified as $u_{1}(t)-v=a_{0}+a_{1} t$ and $u_{2}(t)-v=b_{0}+b_{1} t$, respectively. When travel time is deterministic and fixed, the optimality condition require that $a_{0}+a_{1} t_{\mathrm{d} 1}^{*}=b_{0}+b_{1}\left[t_{\mathrm{d} 1}^{*}+T_{1}\right]$, from which we obtain the optimal departure time $t_{\mathrm{d} 1}^{*}=\left[a_{0}-b_{0}-b_{1} T_{1}\right] /\left[b_{1}-a_{1}\right]$ and, by inserting this in the optimality condition, the value of time $-d U^{*} / d T_{1}=\left[a_{0} b_{1}-a_{1} b_{0}-a_{1} b_{1} T_{1}\right] /\left[b_{1}-a_{1}\right]$ (cf. Fosgerau and Engelson, 2011).

A linear specification of our two trip model in which activity 2 is arbitrarily flexible gives

$$
\begin{aligned}
& u_{1}(t)-v=a_{0}+a_{1} t, \\
& u_{2}\left(t-\xi t_{\mathrm{s} 2}\right)-v= \begin{cases}b_{0}+b_{1}\left[t-\xi t_{\mathrm{s} 2}\right] & t-\xi t_{\mathrm{s} 2} \leqslant \underline{t}, \\
c_{0}+c_{1}\left[t-\xi t_{\mathrm{s} 2}\right] & t-\xi t_{\mathrm{s} 2}>\bar{t}\end{cases} \\
& u_{3}(t)-v=d_{0}+d_{1} t,
\end{aligned}
$$

where $\underline{t}$ and $\bar{t} \geqslant \underline{t}$ represent the end of the warm-up period and the start of the cool-down period, respectively. The values of $u_{2}\left(t-\xi t_{\mathrm{s} 2}\right)-v$ between those points do not influence our analysis. Our assumptions about the shape of the marginal utilities imply that $a_{1}<0, b_{1}>0, c_{1}<0$ and $d_{1}>0$.

With the linear specification the flexibility parameter $\xi$ has a particularly clear interpretation. Suppose that at any point in time the marginal activity utility is given by the sum of a linear function of the time of day, $x_{0}+x_{1} t$, and a linear function of the activity duration, $y_{0}+y_{1}\left[t-t_{\mathrm{s} 2}\right]$. That is, $u_{2}\left(t ; t_{\mathrm{s} 2}\right)-v=x_{0}+x_{1} t+y_{0}+y_{1}\left[t-t_{\mathrm{s} 2}\right]$. By identifying $b_{0}=x_{0}+y_{0}, b_{1}=x_{1}+y_{1}$ and $\xi=y_{1} /\left[x_{1}+y_{1}\right]$, this can also be written as $u_{2}\left(t ; t_{\mathrm{s} 2}\right)-v=b_{0}+b_{1}\left[t-\xi t_{\mathrm{s} 2}\right]$, and thus the two formulations are equivalent. We see that the flexibility parameter $\xi$ represents the relative influence of the activity duration over the time of day on the marginal utility.

In Appendix A we show that when the departure time on trip 2 is chosen optimally in response to the arrival time on trip 1 , the backward optimal marginal utility $\tilde{u}_{2}\left(t_{\mathrm{s} 2}\right)$ is a linear function. That is, the linearity property is preserved when scheduling flexibility is introduced, and the optimality conditions for trip 1 can be written as

$$
a_{0}+a_{1} t_{\mathrm{d} 1}^{*}=\tilde{b}_{0}+\tilde{b}_{1}\left[t_{\mathrm{d} 1}^{*}+T_{1}\right]
$$

where

$$
\begin{aligned}
& \tilde{b}_{0}=[1-\xi] b_{0}+\xi \frac{c_{0} d_{1}-c_{1} d_{0}-c_{1} d_{1} T_{2}}{d_{1}-c_{1}}, \\
& \tilde{b}_{1}=[1-\xi]^{2} b_{1}-\xi^{2} \frac{c_{1} d_{1}}{d_{1}-c_{1}},
\end{aligned}
$$

are the parameters of the linear backward optimal marginal utility function. The value of time is

$$
-\frac{d U^{*}}{d T_{1}}=\frac{a_{0} \tilde{b}_{1}-a_{1} \tilde{b}_{0}-a_{1} \tilde{b}_{1} T_{1}}{\tilde{b}_{1}-a_{1}},
$$

which is linearly increasing in the travel times on both trip 1 and (except with $\xi=0$ ) on trip 2. As expected, we recover $\tilde{b}_{0}=b_{0}$ and $\tilde{b}_{1}=b_{1}$ with $\xi=0$. With $\xi=1$ we obtain the value of time $-d U^{*} / d T_{1}=\left[-a_{0} c_{1} d_{1}-a_{1} c_{0} d_{1}+a_{1} c_{1} d_{0}+a_{1} c_{1} d_{1}\left[T_{1}+\right.\right.$ $\left.\left.T_{2}\right]\right] /\left[a_{1} c_{1}-a_{1} d_{1}-c_{1} d_{1}\right]$ (the general theory then tells us that $-d U^{*} / d T_{2}=-d U^{*} / d T_{1}$ ). 
As shown in Appendix A, corresponding results hold for the evening trip. Our results imply that the analysis of the value of travel time variance performed by Fosgerau and Engelson (2011) can be generalized to schedules involving multiple trips and activities with flexible scheduling. They are also potentially useful for numerical applications of activity-based models. Since linearity is preserved for any level of flexibility, formulas (21)-(23) can be applied recursively over a sequence of activities to obtain a linear backward optimal marginal utility and optimal trip timing at any point in time during the day. The requirement for this to hold is that all activity marginal utilities are expressed in linear form.

\section{Travel time prediction and delay costs}

To calculate the cost of journey delay we assume that travelers always seek to optimize their daily schedules given their perceptions about future travel conditions. In general, travelers may underpredict, overpredict or in ideal cases perfectly predict the travel times on subsequent trips. The travelers' predictive accuracy is treated as exogenous to our model, but can be assumed to depend on the provision of travel information, among other factors. In a more complete framework, our analysis should be proceeded by a model of the cognitive processes that lead to a particular prediction about travel times as output (see, e.g., Jha et al., 1998; Chen and Mahmassani, 2004).

At what time a traveler chooses to depart from activity 1 depends on her predictions about the travel times on both trip 1 and (in general) trip 2. Having arrived at activity 2, the choice of departure time from that activity depends on the time of arrival, which is determined by her departure time from activity 1 and the actual realized travel time on trip 1 , and her possibly updated prediction about the travel time on trip 2. Due to her experiences on trip 1 and any travel information received throughout the day, this prediction may be different from her prediction before departing from activity 1.4

Let $T_{1}^{0}\left(t_{\mathrm{d} 1}\right)$ and $T_{2}^{0}\left(t_{\mathrm{d} 2}\right)$ denote the normal, baseline travel times and let $T_{1}\left(t_{\mathrm{d} 1}\right)$ and $T_{2}\left(t_{\mathrm{d} 2}\right)$ denote the (actual) travel times that the traveler suffers during a certain disruption scenario. Remember that travel times are modeled as deterministic variables. Here we will only consider the case when $T_{i}\left(t_{\mathrm{d} i}\right)>T_{i}^{0}\left(t_{\mathrm{d} i}\right)$, although the model may also be used to study cases when travel conditions are better than expected, i.e., $T_{i}\left(t_{\mathrm{d} i}\right)<T_{i}^{0}\left(t_{\mathrm{d} i}\right), i=1,2$. The journey delay is $\Delta T_{i}\left(t_{\mathrm{d} i}\right)=T_{i}\left(t_{\mathrm{d} i}\right)-$ $T_{i}^{0}\left(t_{\mathrm{d} i}\right), i=1,2$.

For the subsequent analysis in this paper, it will be convenient to model the traveler's predictions about the journey delays before departing from activity 1 as two factors $\eta_{1}^{1}$ and $\eta_{2}^{1}$, so that the traveler predicts the travel times to be $\breve{T}_{1}^{1}\left(t_{\mathrm{d} 1}\right)=T_{1}^{0}\left(t_{\mathrm{d} 1}\right)+\eta_{1}^{1} \Delta T_{1}\left(t_{\mathrm{d} 1}\right)$ and $\breve{T}_{2}^{1}\left(t_{\mathrm{d} 2}\right)=T_{2}^{0}\left(t_{\mathrm{d} 2}\right)+\eta_{2}^{1} \Delta T_{2}\left(t_{\mathrm{d} 2}\right)$. Similarly, her prediction about the journey delay on trip 2 before departing from activity 2 is represented as a factor $\eta_{2}^{2}$, so that the predicted travel time is $\check{T}_{2}^{2}\left(t_{\mathrm{d} 2}\right)=T_{2}^{0}\left(t_{\mathrm{d} 2}\right)+$ $\eta_{2}^{2} \Delta T_{2}\left(t_{\mathrm{d} 2}\right)$.

It can be seen that parameter values $\eta_{i}^{j}=1$ represent perfect predictions of the journey delays, $\eta_{i}^{j}>1$ represent overprediction and values $0 \leqslant \eta_{i}^{j}<1$ represent underprediction. Parameter values $\eta_{i}^{j}=0$ represent complete ignorance about the deteriorated travel conditions. Modeling perception errors as multipliers to the delay, and not to the total travel time, allows us to make direct comparisons of the delay costs under different prediction profiles as the duration of the delay varies. In practice, the prediction parameters would be functions of previous experience, information and personal characteristics.

On trip 1 the traveler then chooses a departure time $\breve{t}_{d 1}$ that maximizes utility given the predicted travel times, i.e., $\check{t}_{d 1} \equiv \arg \max _{t_{\mathrm{d} 1}} U\left(t_{\mathrm{d} 1}, t_{\mathrm{d} 2}^{*}\left(t_{\mathrm{d} 1}+\check{T}_{1}^{1}\left(t_{\mathrm{d} 1}\right)\right) ; \check{T}_{1}^{1}, \check{T}_{2}^{1}\right)$. Similarly, on trip 2 the traveler chooses departure time $\check{t}_{d 2}$ based on the actual arrival time and the possibly updated travel time prediction, satisfying $\check{t}_{d 2} \equiv \arg \max _{t_{\mathrm{d} 2}} U\left(\check{t}_{d 1}, t_{\mathrm{d} 2} ; T_{1}, \breve{T}_{2}^{2}\right)$. Assuming that the utility function is money metric and represents, say, the compensating variation relative to the baseline situation $\left(t_{\mathrm{d} 1}^{*}, t_{\mathrm{d} 2}^{*}, T_{1}^{0}, T_{2}^{0}\right)$, a money cost of the delay can be evaluated as the difference

$$
\Delta C\left(T_{1}^{0}, T_{2}^{0}, \Delta T_{1}, \Delta T_{2}, \eta_{1}^{1}, \eta_{2}^{1}, \eta_{2}^{2}\right)=U\left(t_{\mathrm{d} 1}^{*}, t_{\mathrm{d} 2}^{*} ; T_{1}^{0}, T_{2}^{0}\right)-U\left(\check{t}_{d 1}, \check{t}_{d 2} ; T_{1}, T_{2}\right) .
$$

Fig. 2 shows how utility losses due to delays occur during the day for the same generic set of marginal utility curves as in Fig. 1 -in particular, activity 2 is assumed to be semi-flexible $(\xi=0.5)$. At any time, a cost (shown in dark shade) or gain (shown in light shade) arises proportionally to the difference between the current marginal utility and the marginal utility at the same time before the disruption. The three diagrams show the losses with three different prediction profiles $\left(\eta_{1}^{1}, \eta_{2}^{1}, \eta_{2}^{2}\right)$ : The top diagram shows the case $(1,1,1)$, i.e., perfect travel time prediction on both trips. The middle diagram shows the case $(1.5,1.5,1.5)$, i.e., overprediction of delays by $50 \%$ on both trips with no updating during the day. The bottom diagram shows the case $(0,0,0)$, i.e., complete ignorance of the delays on both trips without updating.

The top graph in Fig. 2 shows that when the travel times on both trips are perfectly predicted, the traveler will depart earlier on both trips in order to distribute the lost time optimally between activities. The middle graph shows that when the delay is overestimated, the traveler departs too early on both trips. The bottom graph shows that with complete ignorance about the delays, the traveler departs as normal in the morning and, in order to compensate for the late arrival at work, even later than normal in the evening, leading to a very late arrival at home.

\footnotetext{
${ }^{4}$ Another possible way of responding to expected long journey delays is to cancel the trip altogether. Some individuals, for example, may gain more by working from home one day, yielding utility $U_{h}$, than traveling to work with long delays. Cancelling the trip is preferred if the predicted utility lost from spending time traveling is greater than the predicted utility gained from taking part in the activity itself, so that $U<U_{h}$. Trip cancellation is not considered further in this paper but could be incorporated in the model as a discrete decision variable that precedes the choices of departure times.
} 

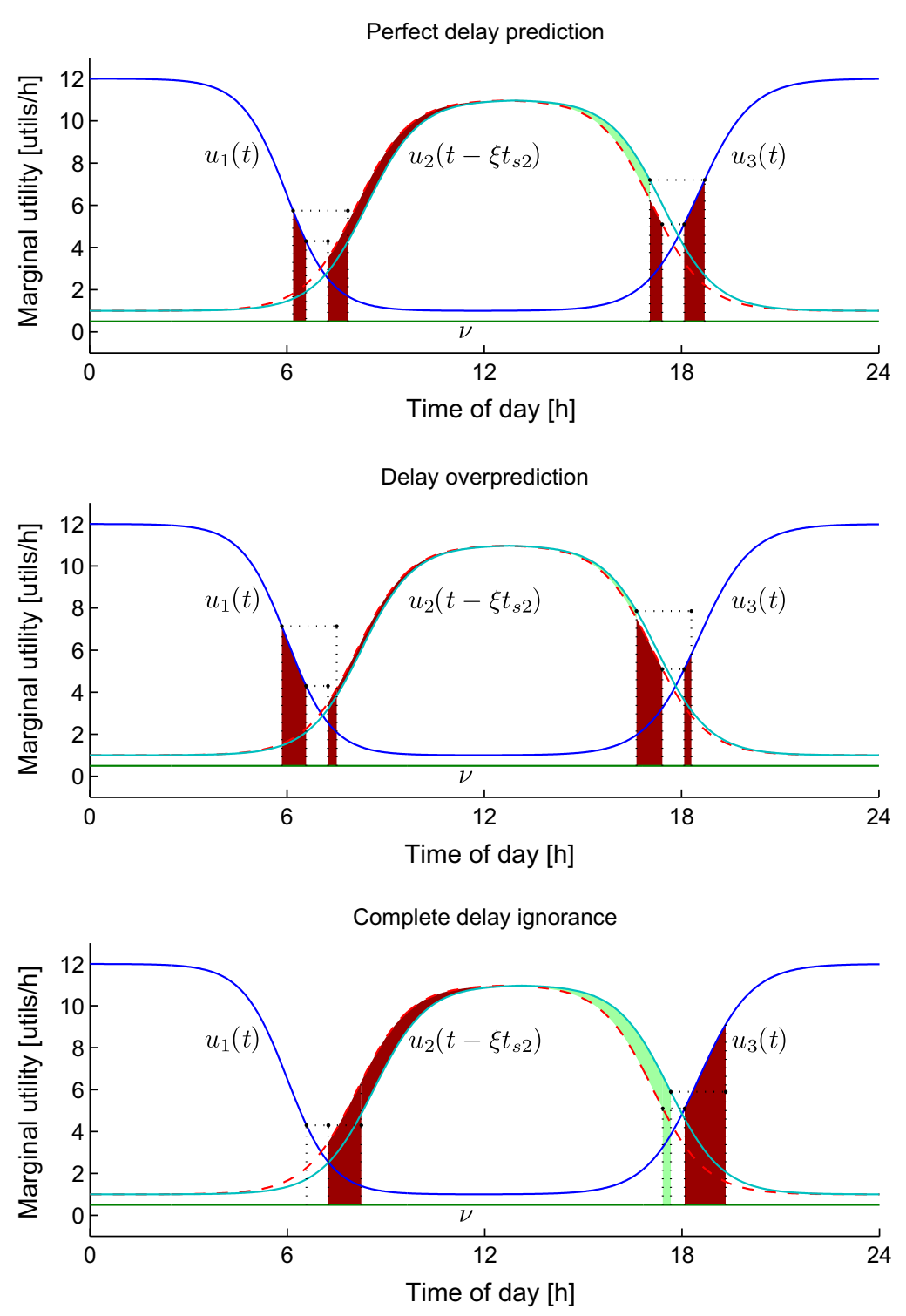

Fig. 2. Utility losses due to journey delay under different delay prediction profiles and a semi-flexible work schedule. Solid curves show generic marginal activity utilities, dashed curves show pre-disruption optimal marginal utilities, dotted lines mark the intervals spent traveling. Dark areas show utility losses, light areas show utility gains. Symmetric baseline travel times $(2 \times 40 \mathrm{~min})$ and journey delays $(2 \times 60 \mathrm{~min})$ independent of departure times. Top: Perfect delay prediction. Middle: Delay overprediction. Bottom: Complete delay ignorance.

\section{Numerical example}

As described in Section 3, the effect of a journey delay $\Delta T$ for a given traveler is a cost $\Delta C$ that depends on the magnitude and distribution of the journey delay on trip 1 and $2\left(\Delta T_{1}, \Delta T_{2}\right)$, the baseline travel time on both trips $\left(T_{1}^{0}, T_{2}^{0}\right)$, and the traveler's predictions about the delays $\left(\eta_{1}^{1}, \eta_{2}^{1}, \eta_{2}^{2}\right)$. Between travelers the impact depends on preferences and flexibility as captured by the shapes of the marginal cost functions. In this section we investigate numerically how the delay cost depends on the delay duration and its distribution on different trips during the day, the accuracy of delay prediction and travel information, and the scheduling flexibility of work hours. To study the influence of scheduling flexibility explicitly, we consider the two extreme cases when activity 2 is completely fixed $(\xi=0)$ and flexible $(\xi=1)$, respectively.

\subsection{Cost specifications and calibration}

Tseng and Verhoef (2008) estimated the time-varying willingness to pay for spending time at home and at work in the morning relative to traveling. Considering that work hours may be at least partially flexible, this corresponds to the marginal 
Table 1

Calibrated parameter values for the activity marginal utility functions. In the analysis, the flexibility parameter $\xi$ is set to either 0 or 1 , and the location parameters $\left(\omega_{2}^{1}, \omega_{2}^{2}\right)$ are adjusted to $(0.292,0.688)$ with $\xi=0$ and to $(-0.008,0.388)$ with $\xi=1$. All other parameters remain the same.

\begin{tabular}{lll}
\hline Activity 1 (morning home) & Activity 2 (work) & Activity 3 (evening home) \\
\hline$\alpha_{1}^{\max }=19($ Euro $/ \mathrm{h})$ & $\alpha_{2}^{\max }=25($ Euro $/ \mathrm{h})$ & $\alpha_{3}^{\max }=\alpha_{1}^{\max }($ Euro $/ \mathrm{h})$ \\
$\alpha_{1}^{\min }=-10($ Euro $/ \mathrm{h})$ & $\alpha_{2}^{\min }=-35($ Euro $/ \mathrm{h})$ & $\alpha_{3}^{\min }=\alpha_{1}^{\min }($ Euro $/ \mathrm{h})$ \\
$\phi_{1}=60\left(\right.$ day $\left.^{-1}\right)$ & $\phi_{2}^{1}=80\left(\right.$ day $\left.^{-1}\right)$ & $\phi_{3}=65\left(\right.$ day $\left.^{-1}\right)$ \\
$\omega_{1}=0.271$ (day) & $\phi_{2}^{2}=40\left(\right.$ day $\left.^{-1}\right)$ & $\omega_{3}=0.708($ day $)$ \\
& $\omega_{2}^{1}=0.232($ day) & \\
& $\omega_{2}^{2}=0.628($ day $)$ & \\
& $\xi=0.20$ & \\
\hline
\end{tabular}

cost functions $\alpha_{1}(t)=u_{1}(t)-v$ and $\tilde{\alpha}_{2}(t)=\tilde{u}_{2}(t)-v$, respectively (see Section 2.5). Their framework was based on a stated preference survey of trip timing choices among discrete predefined time intervals, and they specified a mixed logit model to estimate willingness to pay values in each time interval.

We have calibrated marginal cost functions in a manual procedure to replicate the mean willingness to pay results of Tseng and Verhoef (2008) as well as to give reasonable departure times on both trips in the baseline situation. ${ }^{5}$ Of course, since we model the entire day and the empirical study only considered the morning commute, there are some remaining degrees of freedom in the functions for which assumptions need be made, in particular regarding the evening commute and the scheduling flexibility. Some further empirical hints can be obtained from Hess et al. (2007), who estimated a joint scheduling model for the morning and evening commutes of the Small (1982) type and found, loosely speaking, that the costs associated with early and late departure from work are typically smaller than the costs of early and late arrival to work. Still, the results presented in this paper should be seen mainly as an illustration of the approach, to be followed by more rigorous estimation and more reliable results in future work.

We use logistic functions to represent the time-varying marginal utility, capturing the warm-up and cool-down periods of each activity. We interpret activities 1 and 3 as being at home in the morning and the evening, respectively, and specify the marginal cost functions $\alpha_{1}(t)=u_{1}(t)-v$ and $\alpha_{3}(t)=u_{3}(t)-v$ as

$$
\begin{array}{ll}
\alpha_{1}(t)=\alpha_{1}^{\max }-\frac{\alpha_{1}^{\max }-\alpha_{1}^{\min }}{1+\exp \left(-\phi_{1}\left[t-\omega_{1}\right]\right)} & 0 \leqslant t \leqslant 1, \\
\alpha_{3}(t)=\alpha_{3}^{\min }+\frac{\alpha_{3}^{\max }-\alpha_{3}^{\min }}{1+\exp \left(-\phi_{3}\left[t-\omega_{3}\right]\right)} & 0 \leqslant t \leqslant 1,
\end{array}
$$

where $\alpha_{i}^{\max }$ and $\alpha_{i}^{\min }, i=1,3$, are upper and lower limits for the willingness to pay for being at home in the morning and the evening, respectively, rather than traveling. Since being at home is essentially one single activity, we restrict the parameters so that $\alpha_{1}^{\max }=\alpha_{3}^{\max }$ and $\alpha_{1}^{\min }=\alpha_{3}^{\min }$. The parameters $\omega_{i}$ control the timing of the cool-down and warm-up periods, while $\phi_{i}$ control the durations of the same periods (larger values meaning swifter changes).

Similarly, the marginal cost of the work activity $\alpha_{2}\left(t-\xi t_{\mathrm{s} 2}\right)=u_{2}\left(t-\xi t_{\mathrm{s} 2}\right)-v$ is specified as

$$
\alpha_{2}\left(t-\xi t_{\mathrm{s} 2}\right)= \begin{cases}\alpha_{2}^{\min }+\frac{\alpha_{2}^{\max }-\alpha_{2}^{\min }}{1+\exp \left(-\phi_{2}^{1}\left[t-\xi t_{52}-\omega_{2}^{1}\right]\right)} & 0 \leqslant t-\xi t_{\mathrm{s} 2} \leqslant t_{2}^{\text {shift }}, \\ \alpha_{2}^{\max }-\frac{\alpha_{2}^{\max }-\alpha_{2}^{\min }}{1+\exp \left(-\phi_{2}^{2}\left[t-\xi_{\mathrm{s} 2}-\omega_{2}^{2}\right]\right)} & t_{2}^{\text {shift }}<t-\xi t_{\mathrm{s} 2} \leqslant 1 .\end{cases}
$$

Here, parameters $\omega_{2}^{1}$ and $\omega_{2}^{2}$, together with the flexibility parameter $\xi$ and arrival time $t_{\mathrm{s} 2}$, control the timing of the warm-up and cool-down periods, while $\phi_{2}^{1}$ and $\phi_{2}^{2}$ control the duration of each period. The transition between the two phases occurs when the marginal utilities intersect, which is at $t_{2}^{\text {shift }}=\left[\phi_{2}^{1} \omega_{2}^{1}+\phi_{2}^{2} \omega_{2}^{2}\right] /\left[\phi_{2}^{1}+\phi_{2}^{2}\right]$. Again, $\alpha_{2}^{\max }$ and $\alpha_{2}^{\min }$ are upper and lower limits, respectively, for the willingness to pay for being at work rather than traveling.

Table 1 shows the calibrated parameter values. In the calibration we assumed a travel time of $40 \mathrm{~min}$ for trip 2 . To reduce the degrees of freedom, the flexibility parameter $\xi$ was set to 0.2 before the other parameters were calibrated. In the analysis below, the flexibility parameter $\xi$ is set to either 0 or 1 , and the location parameters $\left(\omega_{2}^{1}, \omega_{2}^{2}\right)$ are adjusted to $(0.292,0.688)$ with $\xi=0$ and to $(-0.008,0.388)$ with $\xi=1$. These values were chosen to give approximately the same values of time for the fixed and the flexible schedules in the baseline situation. All other parameters remain the same. Fig. 3 shows the marginal cost curves $\alpha_{1}(t), \alpha_{2}\left(t-\xi t_{\mathrm{s} 2}^{*}\right)$ and $\alpha_{3}(t)$ with the calibrated parameter values. Fig. 4 shows the marginal cost curves for the morning trip in comparison with the corresponding empirical results reported by Tseng and Verhoef (2008).

\footnotetext{
${ }^{5}$ As we adopt the model formulation of Ettema and Timmermans (2003), it would seem natural to make use of the marginal utility functions proposed and estimated by those authors. However, their utility functions were estimated so as to reproduce observed departure and arrival times at optimum, without any consideration of money trade-offs. Hence, there is no reason to assume that the chosen scale of utility in that paper represents the travelers' willingness to pay for different schedules.
} 


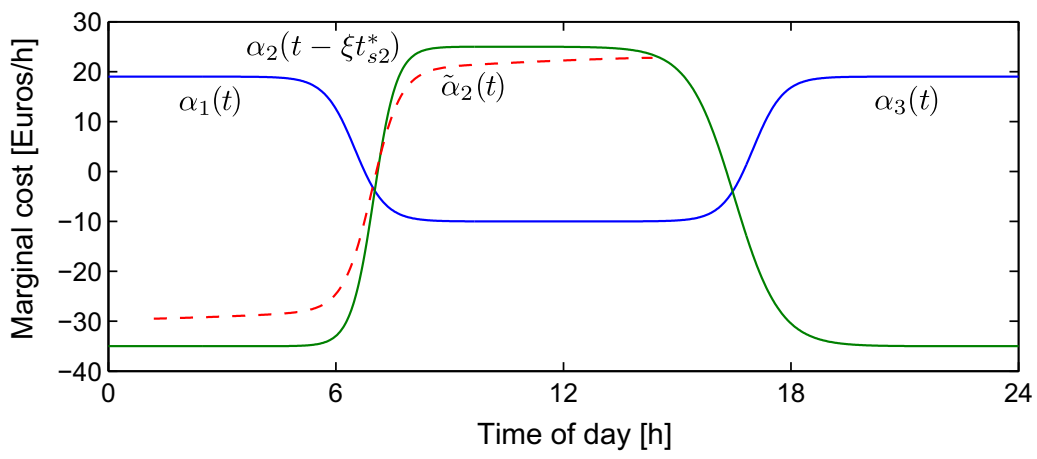

Fig. 3. Calibrated marginal cost functions based on the parameter values shown in Table 1 . The curves represent the case when travel time is $2 \times 40$ min.

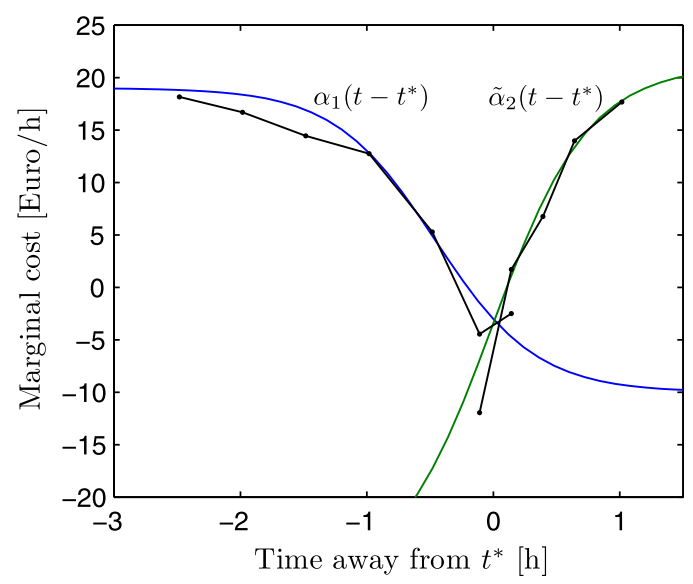

Fig. 4. Calibrated marginal cost functions relative to the ideal transition time $t^{*}$ based on the parameter values shown in Table 1 . The dots joined by lines show the values estimated by Tseng and Verhoef (2008).

\subsection{Results: traveler costs of journey delay}

\subsubsection{Brief disruptions}

First we consider two scenarios in which the journey delay is concentrated to only one of the trips during the day. Thus, the first scenario is a brief disruption (e.g., a severe car crash) that only affects the travel time on trip 1; the second scenario is a disruption that occurs later in the day and only affects the travel time on trip 2.

For the travelers' predictions of travel times we consider a number of stylized cases or profiles, each represented by a set of values for the parameters $\left(\eta_{1}^{1}, \eta_{2}^{1}, \eta_{2}^{2}\right)$ (see Section 3). For the morning disruption scenario it is sufficient to represent each case with the single parameter $\eta_{1}^{1}$, since delay only occurs on trip 1 . We thus consider the three basic prediction profiles $\eta_{1}^{1} \in\{0,1.5,1\}$. These represent complete ignorance of the delay, delay overprediction by $50 \%$ and perfect delay prediction, respectively. For trip 2 we assume that all travelers are informed that the disruption is over and are able to adjust the departure time optimally given the arrival time to work.

Correspondingly, since there is no delay on trip 1, each prediction profile for the evening disruption scenario can be represented by the parameters $\left(\eta_{2}^{1}, \eta_{2}^{2}\right)$, representing the initial and the updated perceptions of the delay on trip 2 . We consider the prediction profiles $(0,0),(0,1.5)$ and $(0,1)$. Thus, we assume that all travelers are uninformed of the disruption to occur later in the day when they depart in the morning and make no adjustment of the departure time for trip 1 . Once arrived at activity 2, we then consider that the scheduling of trip 2 may be based on continued delay ignorance, overprediction by $50 \%$ or perfect delay prediction. Note the asymmetry in possible responses to the morning and evening scenarios (that is, before and after the event), which is a fundamental feature of unexpected events.

Fig. 5 shows the delay cost in each of the two alternative scenarios for a fixed (left) and a flexible (right) work schedule. The baseline travel time is set to $40 \mathrm{~min}$ on both trips. Baseline travel times and delays are independent of departure times, i.e., there is no time-varying congestion.

The delay costs increase rapidly for all prediction profiles, although at diminishing rates, reflecting the shapes of the marginal cost functions. The span in which the delay costs vary depending on the travelers' predictions ability is wider with a 

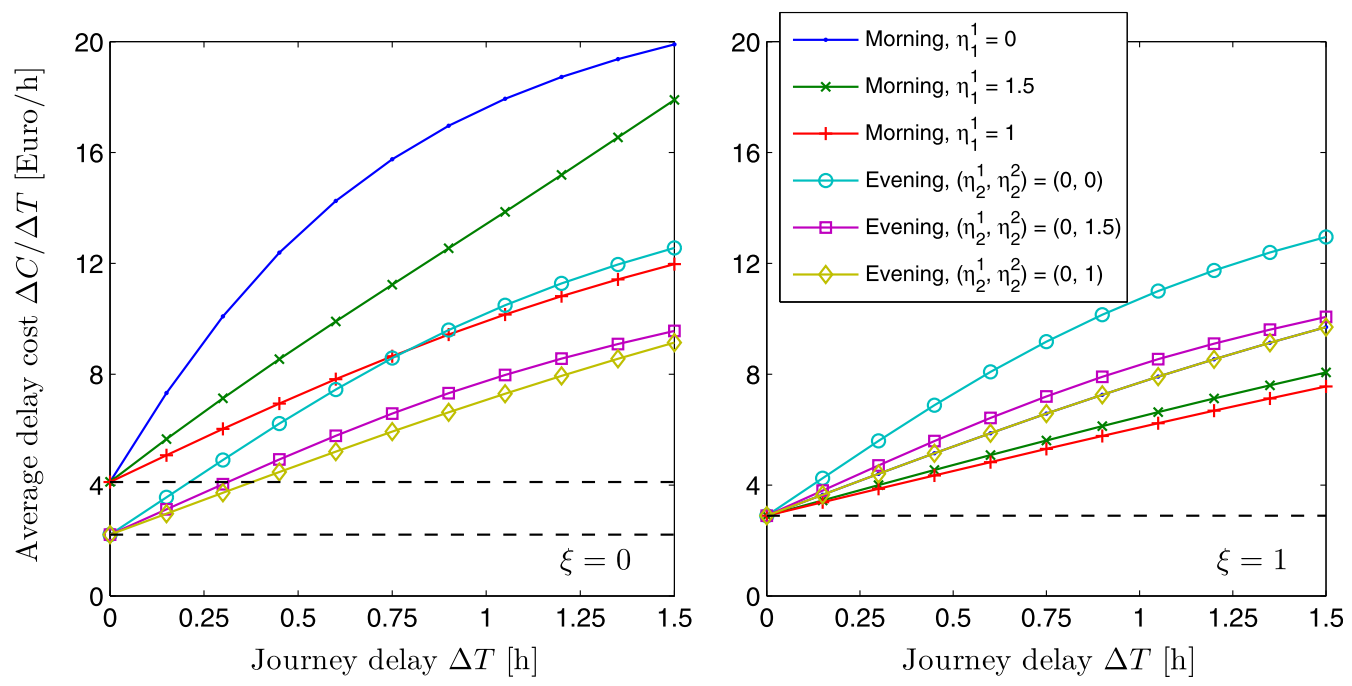

Fig. 5. Average delay cost per hour delay, $\Delta C / \Delta T$, with delay only on the morning trip or only on the evening trip. Curves represent different delay predictions; see the text. Dashed lines show marginal values of time. Baseline travel time is $2 \times 40$ min. Left: Fixed work schedule ( $\xi=0)$. Right: Flexible work schedule $(\xi=1)$. Note that with $\xi=1$, the curves for morning delay, $\eta_{1}^{1}=0$, and evening delay, $\left(\eta_{2}^{1}, \eta_{2}^{2}\right)=(0,1)$, completely coincide.

fixed than with a flexible work schedule. By construction the delay costs are lowest for the profiles involving perfect prediction, since optimizing the schedule against the actual delays is equivalent to minimizing the travel costs. It may be noted that the calculated values of time appear to be significantly lower than those found in most empirical studies (see, e.g., Abrantes and Wardman, 2011), although they are in line with the results of Tseng and Verhoef (2008).

Considering first the evening disruption scenario, we see that the delay costs under each of the three prediction profiles are very similar with a fixed and a flexible work schedule. In other words, there is in this case no benefit of having a flexible schedule, since there is no more slack in the schedule to make up for the delay that day. For both levels of flexibility, some reduction in cost can be gained from accurately predicting the travel time on the evening trip.

With a fixed work schedule the morning disruption scenario leads to considerably higher costs than the evening disruption scenario. This is because the marginal costs increase more steeply in the morning and there is no possibility to compensate for time lost in the morning later in the day. The costs vary greatly depending on how well the traveler is able to predict the delay and adjust her departure time in the morning. Note that the cost curves for the two scenarios converge to two different values as the delay tends to zero, representing the different values of time on the two trips.

With a fully flexible work schedule the costs for the morning disruption scenario are drastically lower than with a fixed schedule. Furthermore, the costs are lower than with delays only in the evening. This clearly illustrates that flexibility in the timing of activities can have a significant influence on the cost. Note that all cost curves converge to the single value of time as the delay tends to zero. Another effect of a completely flexible work activity is that the costs of the complete ignorance prediction profile $\eta_{1}^{1}=0$ for the morning disruption and the perfect updated prediction profile $\left(\eta_{2}^{1}, \eta_{2}^{2}\right)=(0,1)$ for the evening disruption scenario are identical.

\subsubsection{Long-lasting disruptions}

We also consider the case when journey delay is symmetrical on the two trips, representing a long-lasting traffic disruption. The value of time is calculated for a marginal change in travel time also symmetrical in the two trips. Again, the baseline travel time is $40 \mathrm{~min}$ on each trip, so that results can be compared with Fig. 5 above. For the travelers' predictions of travel times we consider five different sets of values for the parameters $\left(\eta_{1}^{1}, \eta_{2}^{1}, \eta_{2}^{2}\right)$ :

- $(0,0,0)$ : Complete ignorance of the delays on both trips. This prediction profile may represent the upper extreme of an initially uninformed traveler.

- $(0,0,1)$ : Initial ignorance updated with perfect prediction.

- $(1.5,1.5,1.5)$ : Overprediction on both trips by $50 \%$.

- $(1.5,1.5,1)$ : Initial overprediction updated with perfect prediction.

- $(1,1,1)$ : Perfect prediction of the delays on both trips. If the traffic disruption is particularly long-lasting, this should be the steady-state behavior that emerges over time, as travelers learn and adapt to the changed travel conditions.

Results are presented in Fig. 6. With a fixed work schedule the total cost for a given total delay is the sum of the costs on each trip, since the trips are independent. This means that the cost per hour delay under a certain prediction profile is the 

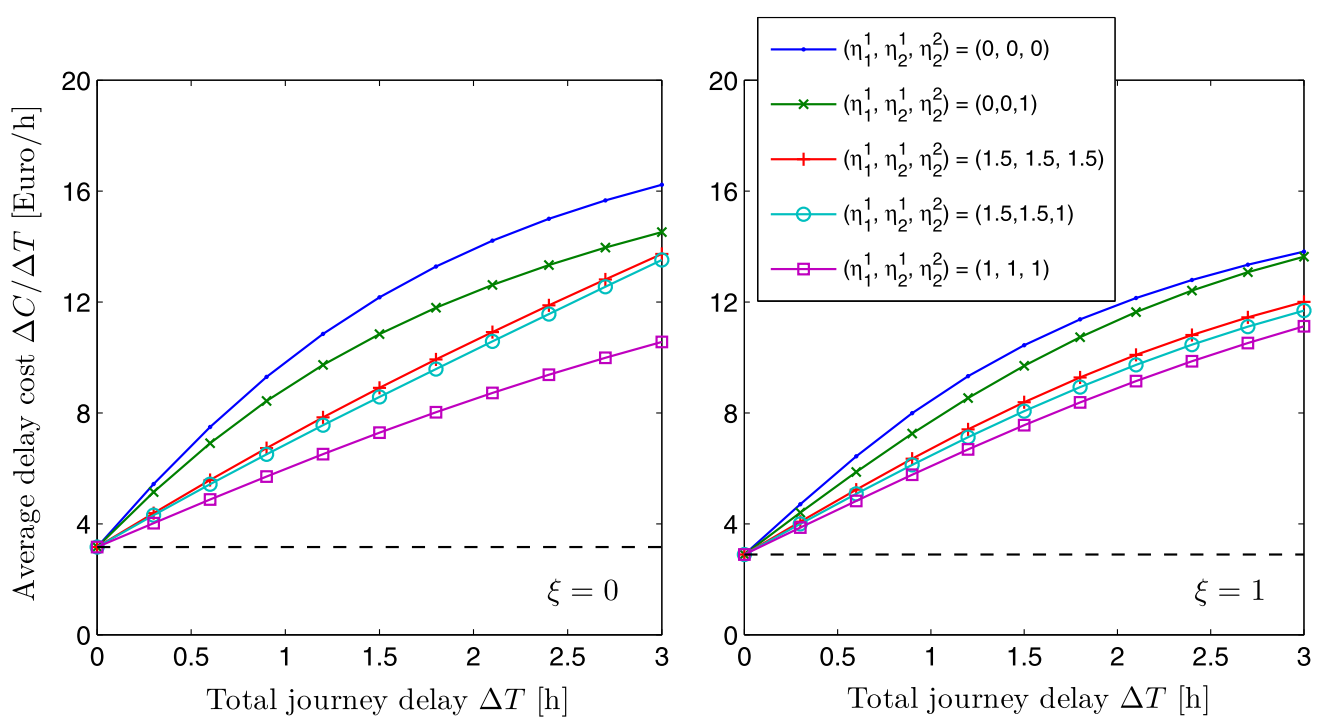

Fig. 6. Average delay cost per hour delay, $\Delta C / \Delta T$, with delay symmetrical on the two trips. Curves represent different delay predictions; see the text. Dashed lines show marginal values of time. Baseline travel time is $2 \times 40 \mathrm{~min}$. Left: Fixed work schedule $(\xi=0)$. Right: Flexible work schedule ( $\xi=1$ ).

average of the costs per hour delay for the corresponding prediction types in the two short-term disruptions considered above, as comparison of Figs. 5 and 6 shows.

A long-lasting disruption reduces the benefit of flexible work hours compared to a brief disruption in the morning, since the evening delay restricts the possibility to postpone the evening trip. Still, the prediction errors have a smaller influence on the costs with a flexible schedule than with a fixed schedule. With flexible scheduling the morning and evening home activities act as "buffers" where most of the lost time is taken under any delay predictions. The cost of overprediction, for example, is low since there is no cost associated with arriving early to work; on the contrary, early arrival gives more time to spend at work and at home in the evening. Except with fixed scheduling and initial delay ignorance, Fig. 6 also shows that there is in general little gain in updating the prediction about the evening.

Repeating the calculations for different baseline travel times, we have found that delay costs become less dependent on the baseline travel time as delays increase. However, the marginal value of time is significantly higher for longer baseline travel times, which means that delay costs relative to the value of time decrease with the baseline travel time. Note that since travel time is treated as exogenous, these are mainly effects of the shape of the marginal utility functions-we have not taken into account that individuals with different utility functions may choose different baseline travel times according to their preferences (self-selection).

\section{Discussion and conclusion}

The main point of this paper has been to extend single trip scheduling models into a multiple trip and activities framework and demonstrate its viability as an approach to evaluating the traveler costs of congestion, traffic disruptions and travel time variability. The modeling framework is able to handle several important aspects of such events: the impact of delay may depend on the flexibility to reschedule activities; lack of information and uncertainty about travel conditions may lead to under- or over-adjustment of the daily schedule in response to the delay; journey delays may be long in relation to normal travel times; delays on more than one trip may restrict the gain from rescheduling activities.

While the model formulation has been proposed previously (Ettema and Timmermans, 2003), this paper is the first to theoretically investigate the effects of scheduling flexibility and the interdependencies between different segments in a daily trip chain on delay costs and the value of time. Modeling travel times as deterministic, we derived optimality conditions for trip departure times, values of time for each trip and optimal schedule adjustments following journey delay. We showed how the single trip scheduling models remain valid in the multiple trip, flexible activity scheduling setting with appropriate generalizations of marginal activity utilities. In particular, we demonstrated that extending the linear single trip model of Fosgerau and Engelson (2011) preserves the linearity of the marginal utility functions, which implies that the findings regarding the value of travel time variance of that paper may also be generalizable.

The numerical calculations show that the average cost per hour delay increase with the delay duration, so that every additional minute of journey delay comes with a higher cost. The cost varies depending on delay prediction (poorer prediction, loosely speaking, giving higher cost) and scheduling flexibility (greater flexibility giving lower cost). Comparing the delay costs under different levels of prediction accuracy provides a way to assess the value of travel information as an instrument to relieve the effects of traffic disturbances. 
The results also show that with a fixed work schedule, a disruption affecting only the morning commute is more costly than if the same total delay is equally distributed on both trips, which in turn is more costly than a disruption affecting only the evening commute. With a flexible work schedule on the other hand, a disruption in the morning only is less costly than a disruption in the evening, reflecting the benefit of being able to adjust the remaining schedule in response to earlier events.

Regarding more extensive and long-lasting transportation network disruptions, the state of practice when estimating the traveler delay costs is to calculate the delays caused by the disruption using a transportation model system, typically based on deterministic or stochastic user equilibrium traffic assignment. The calculated delays are then multiplied with a standard value of time to obtain a monetary cost (Wesemann et al., 1996; Xie and Levinson, in press; MSB, 2009). This approach is adopted also in many model-based studies of road network vulnerability (e.g., Jenelius et al., 2006; Jenelius, 2009; Taylor et al., 2006; Erath et al., 2009). Since relative comparisons between different disruption scenarios are independent of the value of time (assuming a single value for all users), some studies report the delays directly. The results here suggest that this approach underestimates the traveler delay costs, in particular immediately following the disruption when information is likely to be scarce and unreliable.

The model employed here is quite simple, involving only three activities, two trips and two departure times as decision variables. It is desirable to extend the model to include more activities and trips as well as day-to-day dependencies (cf. Arentze et al., 2010). This could also include other choice dimensions such as route, destination and mode choice. Although the rapidly increasing number of decision variables would make the analysis (and estimation) increasingly challenging, the essential features would remain the same: delays will give less time to take part in activities, which leads to costs that depend on scheduling flexibility, information and predictions, etc. The concepts of the backward and forward optimal marginal utility functions, properly generalized, are still relevant for calculating the value of time and delay costs on different trips. It is reasonable to assume that more complex schedules, involving more scheduling constraints, will lead to higher costs in the event of large delays. On the other hand, some delays may be avoided by rearranging the schedule and traveling to other locations, in particular if they occur early in the day.

For future applications of models of this kind there is a need to develop the estimation procedure of the utility functions. For our purposes it is necessary to estimate both individuals' preferences among possible schedules and the substitution rates between money compensations and deviations from the optimal schedules. Estimation of activity-based models is an active current research topic (e.g., Timmermans, 2005). It is also possible that approaches may be adopted from the schedule delay and travel time reliability literature (e.g., Hess et al., 2007).

An important topic for future work is to integrate our cost model with a model of the dynamic traffic evolution following a disruption, that would provide the actual and predicted travel times as input to the cost model (cf. He and Liu, 2010). In a fully integrated model these costs would, in turn, affect traveler's decisions the following days, which give rise to new costs and predictions, etc. Indeed, a cost model such as the present provides an economic foundation for determining the day-today evolution of traffic which is often modeled using quite ad hoc iterative schemes. Another direction for further development is to build on the work of for example Fosgerau and Engelson (2011) and assess the value of reliability by considering stochastic travel times in this flexible scheduling trip chaining framework.

\section{Acknowledgments}

The paper has benefited greatly from comments and suggestions by three anonymous referees. We would also like to thank Marcus Sundberg for helpful comments on an early version of the paper. The work of the first two authors was supported by the Swedish Road Administration and the Swedish Governmental Agency for Innovation Systems (Vinnova). The work of the third author was supported by the National Science Foundation under Grant No. 0825768: BRIDGE: Behavioral Response to the I-35W Disruption: Gauging Equilibration.

\section{Appendix A. Mathematical derivations}

Here we derive trip timing optimality conditions, values of travel time and expressions for the optimal schedule adjustments following marginal changes in travel time in the general case when travel times are functions of departure times, $T_{i}\left(t_{\mathrm{d} i}\right)=T_{i}+T_{\mathrm{xi}}\left(t_{\mathrm{d} i}\right), i=1,2$. For brevity, not all expressions are written out explicitly but can be obtained by merging the constituting components.

Restating Eq. 1, the utility of the daily schedule $\left(t_{\mathrm{d} 1}, t_{\mathrm{d} 2}\right)$ given fixed travel time components $T_{1}, T_{2}$ is

$$
\begin{aligned}
U\left(t_{\mathrm{d} 1}, t_{\mathrm{d} 2} ; T_{1}, T_{2}\right) \equiv & \int_{0}^{t_{\mathrm{d} 1}} u_{1}(t) d t+\int_{t_{\mathrm{d} 1}+T_{1}+T_{\mathrm{x} 1}\left(t_{\mathrm{d} 1}\right)}^{t_{\mathrm{d} 2}} u_{2}\left(t-\xi\left[t_{\mathrm{d} 1}+T_{1}+T_{\mathrm{x} 1}\left(t_{\mathrm{d} 1}\right)\right]\right) d t+\int_{t_{\mathrm{d} 2}+T_{2}+T_{\mathrm{x} 2}\left(t_{\mathrm{d} 2}\right)}^{1} u_{3}(t) d t \\
& +v\left[T_{1}+T_{\mathrm{x} 1}\left(t_{\mathrm{d} 1}\right)+T_{2}+T_{\mathrm{x} 2}\left(t_{\mathrm{d} 2}\right)\right] .
\end{aligned}
$$

First-order partial derivatives are given by

$$
\frac{\partial U}{\partial t_{\mathrm{d} 1}}=u_{1}\left(t_{\mathrm{d} 1}\right)-v-\frac{d t_{\mathrm{s} 2}}{d t_{\mathrm{d} 1}}\left[[1-\xi] u_{2}\left([1-\xi] t_{\mathrm{s} 2}\right)+\xi u_{2}\left(t_{\mathrm{d} 2}-\xi t_{\mathrm{s} 2}\right)-v\right],
$$




$$
\frac{\partial U}{\partial t_{\mathrm{d} 2}}=u_{2}\left(t_{\mathrm{d} 2}-\xi t_{\mathrm{s} 2}\right)-v-\frac{d t_{\mathrm{s} 3}}{d t_{\mathrm{d} 2}}\left[u_{3}\left(t_{\mathrm{s} 3}\right)-v\right],
$$

where $d t_{\mathrm{s} 2} / d t_{\mathrm{d} 1}=1+T_{\mathrm{x} 1}^{\prime}\left(t_{\mathrm{d} 1}\right)$ and $d t_{\mathrm{s} 3} / d t_{\mathrm{d} 2}=1+T_{\mathrm{x} 2}^{\prime}\left(t_{\mathrm{d} 2}\right)$. First-order necessary optimality conditions require that $\partial U / \partial t_{\mathrm{d} 1}=\partial U / \partial t_{\mathrm{d} 2}=0$ at $\left(t_{\mathrm{d} 1}^{*}, t_{\mathrm{d} 2}^{*}\right)$.

\section{A.1. The morning trip}

\section{A.1.1. Backward optimal marginal utility}

It is convenient to denote the utility from the arrival to activity 2 at time $t_{\mathrm{s} 2}$ and onward given departure time $t_{\mathrm{d} 2}$ as

$$
\widetilde{U}_{2}\left(t_{\mathrm{s} 2}, t_{\mathrm{d} 2}\right) \equiv \int_{t_{\mathrm{s} 2}}^{t_{\mathrm{d} 2}} u_{2}\left(t-\xi t_{\mathrm{s} 2}\right) d t+\int_{t_{\mathrm{d} 2}+T_{2}\left(t_{\mathrm{d} 2}\right)}^{1} u_{3}(t) d t+v T_{2}\left(t_{\mathrm{d} 2}\right) .
$$

The "backward optimal" marginal utility function is obtained as

$$
\tilde{u}_{2}\left(t_{\mathrm{s} 2}\right) \equiv-\frac{d \widetilde{U}_{2}\left(t_{\mathrm{s} 2}, t_{\mathrm{d} 2}^{*}\left(t_{\mathrm{s} 2}\right)\right)}{d t_{\mathrm{s} 2}}=[1-\xi] u_{2}\left([1-\xi] t_{\mathrm{s} 2}\right)+\xi u_{2}\left(t_{\mathrm{d} 2}^{*}\left(t_{\mathrm{s} 2}\right)-\xi t_{\mathrm{s} 2}\right),
$$

where the equality follows from the envelope theorem.

\section{A.1.2. Value of time}

An exogenous increase in travel time induces an equal direct delay in arrival time plus in general an indirect change in arrival time due to a change in departure time, i.e.,

$$
\frac{d t_{\mathrm{s} 2}^{*}}{d T_{1}}=1+\frac{d t_{\mathrm{s} 2}^{*}}{d t_{\mathrm{d} 1}} \cdot \frac{d t_{\mathrm{d} 1}^{*}}{d T_{1}}
$$

The travel time on trip 1 affects the optimal departure time on trip 2 only through the arrival time to activity 2 , that is,

$$
\frac{d t_{\mathrm{d} 2}^{*}}{d T_{1}}=\frac{d t_{\mathrm{d} 2}^{*}}{d t_{\mathrm{s} 2}} \cdot \frac{d t_{\mathrm{s} 2}^{*}}{d T_{1}}, \quad \frac{d t_{\mathrm{s} 3}^{*}}{d T_{1}}=\frac{d t_{\mathrm{s} 3}^{*}}{d t_{\mathrm{d} 2}} \cdot \frac{d t_{\mathrm{d} 2}^{*}}{d t_{\mathrm{s} 2}} \cdot \frac{d t_{\mathrm{s} 2}^{*}}{d T_{1}} .
$$

From (30) and (33) we have that at optimum,

$$
\frac{d U^{*}}{d t_{\mathrm{d} 1}}=u_{1}\left(t_{\mathrm{d} 1}^{*}\right)-v-\frac{d t_{\mathrm{s} 2}^{*}}{d t_{\mathrm{d} 1}}\left[\tilde{u}_{2}\left(t_{\mathrm{s} 2}^{*}\right)-v\right]=0 .
$$

We thus have

$$
\frac{d U^{*}}{d T_{1}}=\frac{d t_{\mathrm{d} 1}^{*}}{d T_{1}}\left[u_{1}\left(t_{\mathrm{d} 1}^{*}\right)-v\right]-\frac{d t_{\mathrm{s} 2}^{*}}{d T_{1}}\left[\tilde{u}_{2}\left(t_{\mathrm{s} 2}^{*}\right)-v\right]=\frac{d t_{\mathrm{d} 1}^{*}}{d T_{1}} \cdot \frac{d U^{*}}{d t_{\mathrm{d} 1}}-\left[\tilde{u}_{2}\left(t_{\mathrm{s} 2}^{*}\right)-v\right],
$$

where the first equality follows from the envelope theorem and the second equality follows from (34). From (36) we obtain $-d U^{*} / d T_{1}=\tilde{u}_{2}\left(t_{\mathrm{s} 2}^{*}\right)-v$.

\section{A.1.3. Optimal schedule adjustments}

To satisfy optimality condition (31), a change in arrival time $t_{\mathrm{s} 2}$ incurs an adjustment of the optimal departure time $t_{\mathrm{d} 2}^{*}\left(t_{\mathrm{s} 2}\right) \equiv \arg \max _{t_{\mathrm{d} 2}} \widetilde{U}_{2}\left(t_{\mathrm{s} 2}, t_{\mathrm{d} 2}\right)$. By the rules for implicit differentiation, this is given by

$$
\frac{d t_{\mathrm{d} 2}^{*}}{d t_{\mathrm{s} 2}}=-\frac{\partial^{2} \widetilde{U}_{2} / \partial t_{\mathrm{s} 2} \partial t_{\mathrm{d} 2}}{\partial^{2} \widetilde{U}_{2} / \partial t_{\mathrm{d} 2}^{2}}
$$

evaluated at $\left(t_{\mathrm{s} 2}, t_{\mathrm{d} 2}^{*}\left(t_{\mathrm{s} 2}\right)\right)$, where

$$
\begin{aligned}
& \frac{\partial^{2} \widetilde{U}_{2}}{\partial t_{\mathrm{s} 2} \partial t_{\mathrm{d} 2}}=-\xi u_{2}^{\prime}\left(t_{\mathrm{d} 2}-\xi t_{\mathrm{s} 2}\right), \\
& \frac{\partial^{2} \widetilde{U}_{2}}{\partial t_{\mathrm{d} 2}^{2}}=u_{2}^{\prime}\left(t_{\mathrm{d} 2}-\xi t_{\mathrm{s} 2}\right)-\left[1+T_{\mathrm{x} 2}^{\prime}\left(t_{\mathrm{d} 2}\right)\right]^{2} u_{3}^{\prime}\left(t_{\mathrm{s} 3}\right)-T_{\mathrm{x} 2}^{\prime \prime}\left(t_{\mathrm{d} 2}\right)\left[u_{3}\left(t_{\mathrm{s} 3}\right)-v\right] .
\end{aligned}
$$

Our assumptions that $u_{2}^{\prime}\left(t_{\mathrm{d} 2}-\xi t_{\mathrm{s} 2}\right)<0$ and $u_{3}^{\prime}\left(t_{\mathrm{s} 3}\right)>0$ and fixed travel times give $d t_{\mathrm{d} 2}^{*} / d t_{\mathrm{s} 2} \in[0, \xi]$ for any $\xi$.

In order to calculate $d t_{\mathrm{d} 1}^{*} / d T_{1}$, we obtain the derivative of $\tilde{u}_{2}$ with respect to the arrival time $t_{\mathrm{s} 2}$,

$$
\tilde{u}_{2}^{\prime}\left(t_{\mathrm{s} 2}\right)=[1-\xi]^{2} u_{2}^{\prime}\left([1-\xi] t_{\mathrm{s} 2}\right)+\xi\left[\frac{d t_{\mathrm{d} 2}^{*}\left(t_{\mathrm{s} 2}\right)}{d t_{\mathrm{s} 2}}-\xi\right] u_{2}^{\prime}\left(t_{\mathrm{d} 2}^{*}\left(t_{\mathrm{s} 2}\right)-\xi t_{\mathrm{s} 2}\right) .
$$

Our assumptions about the shape of the marginal utility functions, constant travel times and the fact that $d t_{\mathrm{d} 2}^{*} / d t_{\mathrm{s} 2} \in[0, \xi]$ for any $\xi$ imply that $\tilde{u}_{2}^{\prime}\left(t_{\mathrm{s} 2}\right)>0$, i.e., $\tilde{u}_{2}\left(t_{\mathrm{s} 2}\right)$ is an increasing function. 
Further, the total daily utility given departure times $t_{\mathrm{d} 1}, t_{\mathrm{d} 2}^{*}\left(t_{\mathrm{s} 2}\right)$ and fixed travel time components $T_{1}, T_{2}$ is

$$
U_{1}\left(t_{\mathrm{d} 1} ; T_{1}, T_{2}\right) \equiv U\left(t_{\mathrm{d} 1}, t_{\mathrm{d} 2}^{*}\left(t_{\mathrm{d} 1}+T_{1}+T_{\mathrm{x} 1}\left(t_{\mathrm{d} 1}\right)\right) ; T_{1}, T_{2}\right)
$$

To satisfy optimality condition (30), an increase in travel time $T_{1}$ incurs an adjustment of the optimal departure time $t_{\mathrm{d} 1}^{*}$ given by

$$
\frac{d t_{\mathrm{d} 1}^{*}}{d T_{1}}=-\frac{\partial^{2} U_{1} / \partial t_{\mathrm{d} 1} \partial T_{1}}{\partial^{2} U_{1} / \partial t_{\mathrm{d} 1}^{2}}
$$

evaluated at $t_{\mathrm{d} 1}^{*}$, where

$$
\begin{aligned}
& \frac{\partial^{2} U_{1}}{\partial t_{\mathrm{d} 1} \partial T_{1}}=-\left[1+T_{\mathrm{x} 1}^{\prime}\left(t_{\mathrm{d} 1}\right)\right] \tilde{u}_{2}^{\prime}\left(t_{\mathrm{s} 2}\right), \\
& \frac{\partial^{2} U_{1}}{\partial t_{\mathrm{d} 1}^{2}}=u_{1}^{\prime}\left(t_{\mathrm{d} 1}\right)-\left[1+T_{\mathrm{x} 1}^{\prime}\left(t_{\mathrm{d} 1}\right)\right]^{2} \tilde{u}_{2}^{\prime}\left(t_{\mathrm{s} 2}\right)-T_{\mathrm{x} 1}^{\prime \prime}\left(t_{\mathrm{d} 1}\right)\left[\tilde{u}_{2}\left(t_{\mathrm{s} 2}\right)-v\right] .
\end{aligned}
$$

Our assumptions about the shape of the marginal utility functions and constant travel times give $d t_{\mathrm{d} 1}^{*} / d T_{1} \in[-1,0]$ and $d t_{\mathrm{s} 2}^{*} / d T_{1} \in[0,1]$ for any $\xi$.

\section{A.1.4. Completely fixed and flexible schedules}

Eqs. (38)-(40) and (43)-(45) show that fixed scheduling, $\xi=0$, gives $d t_{\mathrm{d} 2}^{*} / d t_{\mathrm{s} 2}=0$ and, with constant travel times,

$$
\frac{d t_{\mathrm{d} 1}^{*}}{d T_{1}}=\frac{u_{2}^{\prime}\left(t_{\mathrm{s} 2}^{*}\right)}{u_{1}^{\prime}\left(t_{\mathrm{d} 1}^{*}\right)-u_{2}^{\prime}\left(t_{\mathrm{s} 2}^{*}\right)}, \quad \xi=0 .
$$

Flexible schedule, $\xi=1$, with constant travel times gives $d t_{\mathrm{d} 2}^{*} / d t_{\mathrm{s} 2}=u_{2}^{\prime}\left(t_{\mathrm{d} 2}^{*}\left(t_{\mathrm{s} 2}\right)-t_{\mathrm{s} 2}\right) /\left[u_{2}^{\prime}\left(t_{\mathrm{d} 2}^{*}\left(t_{\mathrm{s} 2}\right)-t_{\mathrm{s} 2}\right)-u_{3}^{\prime}\left(t_{\mathrm{s} 3}^{*}\left(t_{\mathrm{s} 2}\right)\right)\right]$ and

$$
\frac{d t_{\mathrm{d} 1}^{*}}{d T_{1}}=\frac{u_{2}^{\prime}\left(t_{\mathrm{d} 2}^{*}-t_{\mathrm{s} 2}^{*}\right) u_{3}^{\prime}\left(t_{\mathrm{s} 3}^{*}\right)}{u_{1}^{\prime}\left(t_{\mathrm{d} 1}^{*}\right) u_{2}^{\prime}\left(t_{\mathrm{d} 2}^{*}-t_{\mathrm{s} 2}^{*}\right)-u_{1}^{\prime}\left(t_{\mathrm{d} 1}^{*}\right) u_{3}^{\prime}\left(t_{\mathrm{s} 3}^{*}\right)-u_{2}^{\prime}\left(t_{\mathrm{d} 2}^{*}-t_{\mathrm{s} 2}^{*}\right) u_{3}^{\prime}\left(t_{\mathrm{s} 3}^{*}\right)}, \quad \xi=1 .
$$

The other departure time and arrival time adjustments can be found by applying the general relationships (34) and (35).

\section{A.2. The evening trip}

The derivations for the evening trip are analogous to those for the morning trip but are carried out here for completeness.

\section{A.2.1. Forward optimal marginal utility}

It is convenient to denote the utility up to the departure from activity 2 at time $t_{\mathrm{d} 2}$ given departure time $t_{\mathrm{d} 1}$ from activity 1 as

$$
\widehat{U}_{2}\left(t_{\mathrm{d} 1}, t_{\mathrm{d} 2}\right) \equiv \int_{0}^{t_{\mathrm{d} 1}} u_{1}(t) d t+\int_{t_{\mathrm{d} 1}+T_{1}\left(t_{\mathrm{d} 1}\right)}^{t_{\mathrm{d} 2}} u_{2}\left(t-\xi\left[t_{\mathrm{d} 1}+T_{1}\left(t_{\mathrm{d} 1}\right)\right]\right) d t+v T_{1}\left(t_{\mathrm{d} 1}\right) .
$$

The "forward optimal" marginal utility function is obtained as

$$
\hat{u}_{2}\left(t_{\mathrm{d} 2}\right) \equiv \frac{d \widehat{U}_{2}\left(t_{\mathrm{d} 1}^{*}\left(t_{\mathrm{d} 2}\right), t_{\mathrm{d} 2}\right)}{d t_{\mathrm{d} 2}}=u_{2}\left(t_{\mathrm{d} 2}-\xi\left[t_{\mathrm{d} 1}^{*}\left(t_{\mathrm{d} 2}\right)+T_{1}\left(t_{\mathrm{d} 1}^{*}\left(t_{\mathrm{d} 2}\right)\right)\right]\right),
$$

where the equality follows from the envelope theorem.

\section{A.2.2. Value of time}

An exogenous increase in travel time induces an equal direct delay in arrival time plus in general an indirect change in arrival time due to a change in departure time, i.e.,

$$
\frac{d t_{\mathrm{s} 3}^{*}}{d T_{2}}=1+\frac{d t_{\mathrm{s} 3}^{*}}{d t_{\mathrm{d} 2}} \cdot \frac{d t_{\mathrm{d} 2}^{*}}{d T_{2}}
$$

The travel time on trip 2 affects the optimal departure time on trip 1 only through the departure time on trip 2, that is,

$$
\frac{d t_{\mathrm{d} 1}^{*}}{d T_{2}}=\frac{d t_{\mathrm{d} 1}^{*}}{d t_{\mathrm{d} 2}} \cdot \frac{d t_{\mathrm{d} 2}^{*}}{d T_{2}}, \quad \frac{d t_{\mathrm{s} 2}^{*}}{d T_{2}}=\frac{d t_{\mathrm{s} 2}^{*}}{d t_{\mathrm{d} 1}} \cdot \frac{d t_{\mathrm{d} 1}^{*}}{d t_{\mathrm{d} 2}} \cdot \frac{d t_{\mathrm{d} 2}^{*}}{d T_{2}} .
$$

From (31) and (49) we have that at optimum,

$$
\frac{d U^{*}}{d t_{\mathrm{d} 2}}=\hat{u}_{2}\left(t_{\mathrm{d} 2}^{*}\right)-v-\frac{d t_{\mathrm{s} 3}^{*}}{d t_{\mathrm{d} 2}}\left[u_{3}\left(t_{\mathrm{s} 3}^{*}\right)-v\right]=0 .
$$


We thus have

$$
\frac{d U^{*}}{d T_{2}}=\frac{d t_{\mathrm{d} 2}^{*}}{d T_{2}}\left[\hat{u}_{2}\left(t_{\mathrm{d} 2}^{*}\right)-v\right]-\frac{d t_{\mathrm{s} 3}^{*}}{d T_{2}}\left[u_{3}\left(t_{\mathrm{s} 3}^{*}\right)-v\right]=\frac{d t_{\mathrm{d} 2}^{*}}{d T_{2}} \frac{d U^{*}}{d t_{\mathrm{d} 2}}-\left[u_{3}\left(t_{\mathrm{s} 3}^{*}\right)-v\right],
$$

where the first equality follows from the envelope theorem and the second equality follows from (50). From (52) we obtain $-d U^{*} / d T_{2}=u_{3}\left(t_{\mathrm{s} 3}^{*}\right)-v$.

\section{A.2.3. Optimal schedule adjustments}

To satisfy optimality condition (30), a change in departure time $t_{\mathrm{d} 2}$ incurs an adjustment of the optimal departure time $t_{\mathrm{d} 1}^{*}\left(t_{\mathrm{d} 2}\right) \equiv \arg \max _{t_{\mathrm{d} 1}} \widehat{U}_{2}\left(t_{\mathrm{d} 1}, t_{\mathrm{d} 2}\right)$. By the rules for implicit differentiation, this is given by

$$
\frac{d t_{\mathrm{d} 1}^{*}}{d t_{\mathrm{d} 2}}=-\frac{\partial^{2} \widehat{U}_{2} / \partial t_{\mathrm{d} 1} \partial t_{\mathrm{d} 2}}{\partial^{2} \widehat{U}_{2} / \partial t_{\mathrm{d} 1}^{2}}
$$

evaluated at $\left(t_{\mathrm{d} 1}^{*}\left(t_{\mathrm{d} 2}\right), t_{\mathrm{d} 2}\right)$, where

$$
\begin{aligned}
& \frac{\partial^{2} \widehat{U}_{2}}{\partial t_{\mathrm{d} 1} \partial t_{\mathrm{d} 2}}=-\xi\left[1+T_{\mathrm{x} 1}^{\prime}\left(t_{\mathrm{d} 1}\right)\right] u_{2}^{\prime}\left(t_{\mathrm{d} 2}-\xi t_{\mathrm{s} 2}\right), \\
& \frac{\partial^{2} \widehat{U}_{2}}{\partial t_{\mathrm{d} 1}^{2}}=u_{1}^{\prime}\left(t_{\mathrm{d} 1}\right)-\left[1+T_{\mathrm{x} 1}^{\prime}\left(t_{\mathrm{d} 1}\right)\right]^{2}\left[[1-\xi]^{2} u_{2}^{\prime}\left([1-\xi] t_{\mathrm{s} 2}\right)-\xi^{2} u_{2}^{\prime}\left(t_{\mathrm{d} 2}-\xi t_{\mathrm{s} 2}\right)\right] \\
& \quad-T_{\mathrm{x} 1}^{\prime \prime}\left(t_{\mathrm{d} 1}\right)\left[[1-\xi] u_{2}\left([1-\xi] t_{\mathrm{s} 2}\right)+\xi u_{2}\left(t_{\mathrm{d} 2}-\xi t_{\mathrm{s} 2}\right)-v\right] .
\end{aligned}
$$

Our assumptions that $u_{1}^{\prime}\left(t_{\mathrm{d} 1}\right)<0, u_{2}^{\prime}\left([1-\xi] t_{\mathrm{s} 2}\right)>0$ and $u_{2}^{\prime}\left(t_{\mathrm{d} 2}-\xi t_{\mathrm{s} 2}\right)<0$ and constant travel times give $d t_{\mathrm{d} 1}^{*} / d t_{\mathrm{d} 2} \in[0,1 / \xi]$ for any $\xi>0$.

In order to calculate $d t_{\mathrm{d} 2}^{*} / d T_{2}$, we obtain the derivative of $\hat{u}_{2}$ with respect to the departure time $t_{\mathrm{d} 2}$,

$$
\hat{u}_{2}^{\prime}\left(t_{\mathrm{d} 2}\right)=\left[1-\xi \frac{d t_{\mathrm{d} 1}^{*}\left(t_{\mathrm{d} 2}\right)}{d t_{\mathrm{d} 2}}\left[1+T_{x 1}^{\prime}\left(t_{\mathrm{d} 1}^{*}\left(t_{\mathrm{d} 2}\right)\right)\right]\right] u_{2}^{\prime}\left(t_{\mathrm{d} 2}-\xi t_{\mathrm{s} 2}^{*}\left(t_{\mathrm{d} 2}\right)\right) .
$$

Our assumptions about the shape of the marginal utility functions, constant travel times and the fact that $d t_{\mathrm{d} 1}^{*} / d t_{\mathrm{d} 2} \in[0,1 / \xi]$ for any $\xi>0$ imply that $\hat{u}_{2}^{\prime}\left(t_{\mathrm{d} 2}\right)<0$, i.e., $\hat{u}_{2}\left(t_{\mathrm{d} 2}\right)$ is an decreasing function.

Further, the total daily utility given departure times $t_{\mathrm{d} 1}^{*}\left(t_{\mathrm{d} 2}\right), t_{\mathrm{d} 2}$ and fixed travel time components $T_{1}, T_{2}$ is

$$
U_{2}\left(t_{\mathrm{d} 2} ; T_{1}, T_{2}\right) \equiv U\left(t_{\mathrm{d} 1}^{*}\left(t_{\mathrm{d} 2}\right), t_{\mathrm{d} 2} ; T_{1}, T_{2}\right)
$$

To satisfy optimality condition (31), an increase in travel time $T_{2}$ incurs an adjustment of the optimal departure time $t_{\mathrm{d} 2}^{*}$ given by

$$
\frac{d t_{\mathrm{d} 2}^{*}}{d T_{2}}=-\frac{\partial^{2} U_{2} / \partial t_{\mathrm{d} 2} \partial T_{2}}{\partial^{2} U_{2} / \partial t_{\mathrm{d} 2}^{2}}
$$

evaluated at $t_{\mathrm{d} 2}^{*}$, where

$$
\begin{aligned}
& \frac{\partial^{2} U_{2}}{\partial t_{\mathrm{d} 2} \partial T_{2}}=-\left[1+T_{\mathrm{x} 2}^{\prime}\left(t_{\mathrm{d} 2}\right)\right] u_{3}^{\prime}\left(t_{\mathrm{s} 3}\right), \\
& \frac{\partial^{2} U_{2}}{\partial t_{\mathrm{d} 2}^{2}}=\hat{u}_{2}^{\prime}\left(t_{\mathrm{d} 2}\right)-\left[1+T_{\mathrm{x} 2}^{\prime}\left(t_{\mathrm{d} 2}\right)\right]^{2} u_{3}^{\prime}\left(t_{\mathrm{s} 3}\right)-T_{\mathrm{x} 2}^{\prime \prime}\left(t_{\mathrm{d} 2}\right)\left[u_{3}\left(t_{\mathrm{s} 3}\right)-v\right] .
\end{aligned}
$$

Our assumptions about the shape of the marginal utility functions and constant travel times give $d t_{\mathrm{d} 2}^{*} / d T_{2} \in[-1,0]$ and $d t_{\mathrm{s} 3}^{*} / d T_{2} \in[0,1]$ for any $\xi$.

A.2.4. Completely fixed and flexible schedules

Eqs. (54)-(56) and (59)-(61) show that fixed scheduling, $\xi=0$, gives $d t_{\mathrm{d} 1}^{*} / d t_{\mathrm{d} 2}=0$ and, with constant travel times,

$$
\frac{d t_{\mathrm{d} 2}^{*}}{d T_{2}}=\frac{u_{3}^{\prime}\left(t_{\mathrm{s} 3}^{*}\right)}{u_{2}^{\prime}\left(t_{\mathrm{d} 2}^{*}\right)-u_{3}^{\prime}\left(t_{\mathrm{s} 3}^{*}\right)}, \quad \xi=0 .
$$

Flexible schedule, $\xi=1$, with constant travel times gives $d t_{\mathrm{d} 1}^{*} / d t_{\mathrm{d} 2}=u_{2}^{\prime}\left(t_{\mathrm{d} 2}-t_{\mathrm{s} 2}^{*}\left(t_{\mathrm{d} 2}\right)\right) /\left[u_{1}^{\prime}\left(t_{\mathrm{d} 1}^{*}\left(t_{\mathrm{d} 2}\right)\right)+u_{2}^{\prime}\left(t_{\mathrm{d} 2}-t_{\mathrm{s} 2}^{*}\left(t_{\mathrm{d} 2}\right)\right)\right]$ and

$$
\frac{d t_{\mathrm{d} 2}^{*}}{d T_{2}}=\frac{u_{1}^{\prime}\left(t_{\mathrm{d} 1}^{*}\right) u_{3}\left(t_{\mathrm{s} 3}^{*}\right)+u_{2}^{\prime}\left(t_{\mathrm{d} 2}^{*}-t_{\mathrm{s} 2}^{*}\right) u_{3}^{\prime}\left(t_{\mathrm{s} 3}^{*}\right)}{u_{1}^{\prime}\left(t_{\mathrm{d} 1}^{*}\right) u_{2}^{\prime}\left(t_{\mathrm{d} 2}^{*}-t_{\mathrm{s} 2}^{*}\right)-u_{1}^{\prime}\left(t_{\mathrm{d} 1}^{*}\right) u_{3}^{\prime}\left(t_{\mathrm{s} 3}^{*}\right)-u_{2}^{\prime}\left(t_{\mathrm{d} 2}^{*}-t_{\mathrm{s} 2}^{*}\right) u_{3}^{\prime}\left(t_{\mathrm{s} 3}^{*}\right)}, \quad \xi=1 .
$$

The other departure time and arrival time adjustments can be found by applying the general relationships (50) and (51). 


\section{A.3. Special case: linear marginal utilities}

Here we assume that travel times are independent of departure times. Restating Eqs. (18)-(20), the linear specification is

$$
\begin{aligned}
& u_{1}(t)-v=a_{0}+a_{1} t, \\
& u_{2}\left(t-\xi t_{\mathrm{s} 2}\right)-v= \begin{cases}b_{0}+b_{1}\left[t-\xi t_{\mathrm{s} 2}\right] & t-\xi t_{\mathrm{s} 2} \leqslant \underline{t}, \\
c_{0}+c_{1}\left[t-\xi t_{\mathrm{s} 2}\right] & t-\xi t_{\mathrm{s} 2}>\bar{t},\end{cases} \\
& u_{3}(t)-v=d_{0}+d_{1} t .
\end{aligned}
$$

First-order optimality conditions are

$$
\begin{aligned}
& 0=a_{0}+a_{1} t_{\mathrm{d} 1}^{*}-[1-\xi] b_{0}-\xi\left[c_{0}+c_{1} t_{\mathrm{d} 2}^{*}\right]-\left[[1-\xi]^{2} b_{1}-\xi^{2} c_{1}\right]\left[t_{\mathrm{d} 1}^{*}+T_{1}\right], \\
& 0=c_{0}+c_{1}\left[t_{\mathrm{d} 2}^{*}-\xi\left[t_{\mathrm{d} 1}^{*}+T_{1}\right]\right]-d_{0}-d_{1}\left[t_{\mathrm{d} 2}^{*}+T_{2}\right] .
\end{aligned}
$$

\section{A.3.1. The morning trip}

From (68) we obtain the optimal departure time of trip 2:

$$
t_{\mathrm{d} 2}^{*}=\frac{c_{0}-d_{0}-d_{1} T_{2}-\xi c_{1}\left[t_{\mathrm{d} 1}^{*}+T_{1}\right]}{d_{1}-c_{1}},
$$

which, after insertion in (67) and collection of terms, gives the optimal departure time of trip 1

$$
t_{\mathrm{d} 1}^{*}=\frac{a_{0}-\tilde{b}_{0}-\tilde{b}_{1} T_{1}}{\tilde{b}_{1}-a_{1}}
$$

and the value of time

$$
-\frac{d U^{*}}{d T_{1}}=a_{0}+a_{1} t_{\mathrm{d} 1}^{*}=\frac{a_{0} \tilde{b}_{1}-a_{1} \tilde{b}_{0}-a_{1} \tilde{b}_{1} T_{1}}{\tilde{b}_{1}-a_{1}},
$$

where

$$
\begin{aligned}
& \tilde{b}_{0}=[1-\xi] b_{0}+\xi \frac{c_{0} d_{1}-c_{1} d_{0}-c_{1} d_{1} T_{2}}{d_{1}-c_{1}}, \\
& \tilde{b}_{1}=[1-\xi]^{2} b_{1}-\xi^{2} \frac{c_{1} d_{1}}{d_{1}-c_{1}} .
\end{aligned}
$$

\section{A.3.2. The evening trip}

From (67) we obtain the optimal departure time of trip 1:

$$
t_{\mathrm{d} 1}^{*}+T_{1}=\frac{-a_{0}+a_{1} T_{1}+[1-\xi] b_{0}+\xi\left[c_{0}+c_{1} t_{\mathrm{d} 2}^{*}\right]}{a_{1}-[1-\xi]^{2} b_{1}+\xi^{2} c_{1}},
$$

which, after insertion in (68) and collection of terms, gives the optimal departure time of trip 2

$$
t_{\mathrm{d} 2}^{*}=\frac{\hat{c}_{0}-d_{0}-d_{1} T_{2}}{d_{1}-\hat{c}_{1}}
$$

and the value of time

$$
-\frac{d U^{*}}{d T_{2}}=\hat{c}_{0}+\hat{c}_{1} t_{\mathrm{d} 2}^{*}=\frac{\hat{c}_{0} d_{1}-\hat{c}_{1} d_{0}-\hat{c}_{1} d_{1} T_{2}}{d_{1}-\hat{c}_{1}}
$$

where

$$
\begin{aligned}
& \hat{c}_{0}=c_{0}+\xi c_{1} \frac{a_{0}-a_{1} T_{1}-[1-\xi] b_{0}-\xi c_{0}}{a_{1}-[1-\xi]^{2} b_{1}+\xi^{2} c_{1}}, \\
& \hat{c}_{1}=c_{1} \frac{a_{1}-[1-\xi]^{2} b_{1}}{a_{1}-[1-\xi]^{2} b_{1}+\xi^{2} c_{1}} .
\end{aligned}
$$

\section{References}

Abrantes, P.A.L., Wardman, M.L., 2011. Meta-analysis of UK values of travel time: an update. Transportation Research Part A 45 (1), 1-17.

Arentze, T.A., Ettema, D., Timmermans, H.J.P., 2010. Incorporating time and income constraints in dynamic agent-based models of activity generation and time use: approach and illustration. Transportation Research Part C 18 (1), 71-83. 
Asensio, J., Matas, A., 2008. Commuters' valuation of travel time variability. Transportation Research Part E 44 (6), 1074-1085.

Ashiru, O., Polak, J.W., Noland, R.B., 2004. Utility of schedules: theoretical model of departure-time choice and activity-time allocation with application to individual activity schedules. Transportation Research Record 1894, 84-98.

Axhausen, K.W., Gärling, T., 1992. Activity-based approaches to travel analysis: conceptual frameworks, models, and research problems. Transport Reviews 12 (4), 323-341.

Bates, J., Polak, J., Jones, P., Cook, A., 2001. The valuation of reliability for personal travel. Transportation Research Part E 37 (2-3), 191-229.

Börjesson, M., Eliasson, J., 2011. On the use of “average delay" as a measure of train reliability. Transportation Research Part A 45 (3), $171-184$.

Bowman, J.L., Ben-Akiva, M.E., 2001. Activity-based disaggregate travel demand model system with activity schedules. Transportation Research Part A 35 (1), $1-28$.

Carrion-Madera, C., Levinson, D., 2010. Value of reliability: high occupancy toll lanes, general purpose lanes, and arterials. Presented at the 4th International Symposium on Transportation Network Reliability, July 2010, Minneapolis, MN.

Carrion-Madera, C., Levinson, D., 2011. Value of travel time reliability: a review of current evidence. Presented at the 2011 Transportation Research Board meeting, Washington, DC, January 2011.

Chen, R., Mahmassani, H.S., 2004. Travel time perception and learning mechanisms in traffic networks. Transportation Research Record 1894, 209-221.

Erath, A., Birdsall, J., Axhausen, K.W., Hajdin, R., 2009. Vulnerability assessment methodology for Swiss road network. Transportation Research Record 2137, $118-126$.

Ettema, D., Timmermans, H., 2003. Modeling departure time choice in the context of activity scheduling behavior. Transportation Research Record 1831, 39-46.

Ettema, D., Bastin, F., Polak, J., Ashiru, O., 2007. Modelling the joint choice of activity timing and duration. Transportation Research Part A 41 (9), 827-841.

Fosgerau, M., Engelson, L., 2011. The value of travel time variance. Transportation Research Part B 45 (1), 1-8.

Fosgerau, M., Karlström, A., 2010. The value of reliability. Transportation Research Part B 44 (1), 38-49.

FWHA, 2008. Travel Time Reliability: Making it there on Time, All the Time. Federal Highway Administration, US Department of Transportation.

He, X., Liu, H., 2010. Modeling the day-to-day traffic evolution process after an unexpected network disruption. Working paper.

Hess, S., Polak, J.W., Daly, A., Hyman, G., 2007. Flexible substitution patterns in models of mode and time of day choice: new evidence from the UK and the Netherlands. Transportation 34 (2), 213-238.

Jara-Diaz, S., 2000. Allocation and valuation of travel time savings. In: Hensher, D., Button, K. (Eds.), Handbook of Transport Modelling. Pergamon Press, Oxford, pp. 303-319.

Jara-Diaz, S.R., Munizaga, M.A., Greeven, P., Guerra, R., Axhausen, K., 2008. Estimating the value of leisure time from a time allocation model. Transportation Research Part B 42 (10), 946-957.

Jenelius, E., 2009. Network structure and travel patterns: explaining the geographical disparities of road network vulnerability. Journal of Transport Geography 17 (3), 234-244.

Jenelius, E., Petersen, T., Mattsson, L.-G., 2006. Importance and exposure in road network vulnerability analysis. Transportation Research Part A 40 (7), 537560.

Jha, M., Madanat, S., Peeta, S., 1998. Perception updating and day-to-day travel choice dynamics in traffic networks with information provision. Transportation Research Part C 6 (3), 189-212.

Karlström, A., 2005. A dynamic programming approach for the activity generation and scheduling problem. In: Timmermans, H. (Ed.), Progress in ActivityBased Analysis. Elsevier Ltd., Oxford, UK, pp. 25-42.

Mas-Colell, A., Whinston, M.D., Green, J.R., 1995. Microeconomic Theory. Oxford University Press, New York.

MSB, 2009. Analys av samhällsekonomisk kostnad: Skredet vid E6 i Småröd, 2006. Swedish Civil Contigencies Agency, Report MSB 0069-09 (in Swedish).

Noland, R.B., Polak, J.W., 2002. Travel time variability: a review of theoretical and empirical issues. Transport Reviews 22 (1), 39-54.

Noland, R.B., Small, K.A., 1995. Travel-time uncertainty, departure time choice, and the cost of morning commutes. Transportation Research Record 1493, $150-158$.

Redmond, L.S., Mokhtarian, P.L., 2001. The positive utility of the commute: modeling ideal commute time and relative desired commute amount. Transportation 28 (2), 179-205.

Small, K.A., 1982. The scheduling of consumer activities: work trips. The American Economic Review 72 (3), 467-479.

Small, K.A., Winston, C., Yan, J., 2005. Uncovering the distribution of motorists' preferences for travel time and reliability. Econometrica 73 (4), 1367-1382.

Taylor, M.A.P., Sekhar, S.V.C., D’Este, G.M., 2006. Application of accessibility based methods for vulnerability analysis of strategic road networks. Networks and Spatial Economics 6 (3-4), 267-291.

Timmermans, H. (Ed.), 2005. Progress in Activity-Based Analysis. Elsevier Ltd., Oxford, UK.

Tseng, Y.-Y., Verhoef, E., 2008. Value of time by time of day: a stated-preference study. Transportation Research Part B 42 (7-8), 607-618.

Vickrey, W.S., 1969. Congestion theory and transport investment. The American Economic Review 59 (2), $251-260$.

Vickrey, W.S., 1973. Pricing, metering, and efficiently using urban transportation facilities. Highway Research Record 476, 36-48.

Wesemann, L., Hamilton, T., Tabaie, S., Bare, G., 1996. Cost-of-delay studies for freeway closures caused by Northridge earthquake. Transportation Research Record 1559, 67-75.

Xie, F., Levinson, D., in press. Evaluating the effects of I-35W bridge collapse on road-users in the Twin Cities metropolitan region. Transport Planning and Technology.

Zhang, X., Yang, H., Huang, H.-J., Zhang, H.M., 2005. Integrated scheduling of daily work activities and morning-evening commutes with bottleneck congestion. Transportation Research Part A 39 (1), 41-50. 